\title{
Maturity Structure of Banking Transactions and Its Role in Predicting Negative Net Worth of Banks ${ }^{1}$
}

\author{
Mikhail Mamonov, Institute of International Studies, \\ MGIMO-University; CERGE-EI, \\ mikhail.mamonov@cerge-ei.cz
}

In this paper, we perform a microeconomic analysis of positive and negative imbalances in the maturity structure of Russian banks' transactions. In particular, using Heckman selection models at the cross-section of Russian banks, we test the ability of such imbalances to predict the probability of the detection of banks' negative net worth and its expected magnitude in advance (three months before negative worth detection). The estimation results show that, first, certain indicators of imbalances do offer 'value added' in predicting 'holes' in banks' capital: taking into account these imbalances in banks' short- and medium-term transactions with households and shortterm transactions with enterprises improves the quality of out-ofsample forecasts. Second, the very division into positive and negative imbalances makes sense: the effects are in many cases found to be opposite with respect to the size and likelihood of negative net worth detection at banks. Third, a separate analysis of banking transactions with households and those with businesses is also of great importance: the effect of imbalances in transactions similar in maturity structure but with different types of economic agents is in many cases opposite in sign. The results may be useful for the Bank of Russia in identifying potentially fragile banks as part of its prudential policy.

Keywords: banks, balance falsifications, negative net worth, Heckman selection model, out-of-sample forecast

JEL Codes: C34, G21, G33
Citation: Mamonov, M. (2020). Maturity Structure of Banking Transactions and Its Role in Predicting Negative Net Worth of Banks. Russian Journal of Money and Finance, 79(2), pp. 70-100.

doi: $10.31477 /$ rjmf.202002.70

\footnotetext{
${ }^{1}$ The study was conducted as part of the Fundamental Research Programme of Higher School of Economics Research University in 2019. The author thanks two anonymous reviewers for their contribution to a substantial improvement of the study.
} 


\section{Introduction}

The Bank of Russia's tighter supervision policy combined with the easing of monetary policy in recent years has brought about a business revival in the Russian banking system, driven again, as in the early 2010s, by consumer lending expansion ${ }^{2}$ by banks remaining in the system, despite the continuing stagnation of macroeconomic performance. The key question now is whether this new equilibrium will be sustainable in the long term for the Bank of Russia and banks under its supervision.

Risks to financial stability still look quite significant. ${ }^{3}$ First, there is still lack of consensus in the expert and academic community as to how five hundred banks, which have gone out of business in the last five-six years following the withdrawal of their banking licences, were able to hide (not only from the regulator but also from other players) their negative net worth (NNW) for such a long time. Also, there is lack of clarity about how many similar banks are still in operation, diminishing investor's confidence in the banking system as a whole, while it is investors who could scale up the banking system's capital, thereby enhancing the system's potential to supply corporate loans to the economy. Second, as the number of banks in operation declines and banking profitability recovers, ${ }^{4}$ it is only logical to expect a rise in the number of those willing to share these profits, i.e., the number of banks operating within the system - in other words, to expect a transition to a new equilibrium. In moving towards this new equilibrium, some banks will find themselves losing competition and will likely resort to falsifying their balance sheets and hiding their negative capital, aiming to retain their banking licences. The remaining part of banks, those which have won the competition, will again share profits until new players enter the system. This gives rise to the cycle of the banking system's long-run development: during the periods in which the number of banks declines, the profits of the remaining players increase, prompting the

\footnotetext{
2 The annual pace of retail lending growth reached $20-21 \%$ in the middle of 2019 , whereas the annual rate of corporate lending expansion was no higher than $10 \%$. This compares with twice as fast retail lending rise in 2012, suggesting significant overheating risks.

${ }^{3}$ One of the reference studies on the assessment of systemic financial risks in the Russian economy, Pestova et al (2017), uses the principal component method to analyse the episodes of the 2008-2009 and 2014-2015 crises on an extensive body of data and arrives at a conclusion about a combination in these periods of external and internal shocks. From this perspective, it makes sense to regard the quantitative conclusions of the current study as estimates of net effects, since we do not carry out a decomposition into external and internal shocks.

${ }^{4}$ Annual return on assets (ROA) (after loan-loss provisions) reached $1.9 \%$ in the middle of 2019 , rebounding after hitting a low of $-0.2 \%$ at the end of the 2015Q3. There are currently 448 banks in operation with 744 banks operating in 2015Q3. Profit is currently shared among a much smaller number of players. We note that the recovery in profits is not only owed to the release of loan-loss provisions in the remaining banks. The key source of profit - net interest income also shows an increase. For illustration, over the period from 2015Q3 to 2019Q2, net loan-loss provisions changed from $-2.3 \%$ to $-1.4 \%$ of the banking system's total assets (release of provisions for a total of almost 1 percentage point (p.p.) of assets), but net interest income also rose from $1.9 \%$ to $2.7 \%$ of the system's total assets.
} 
arrival of new players, a rise in competitive pressure, and a renewed contraction in the number of banks. ${ }^{5}$

How fragile banks' NNW performs in these circumstances is an issue calling for theoretical and empirical study. In our view, NNW protract the cycle of the banking system adjustment - its cleansing of the fragile banks, those which keep potential investors from investing in bank capital and make other banks show even less confidence in one another, thus, hampering lending to the economy. This is what makes a clearer insight into and surveillance over the detection of banks' NNW relevant over the long-term horizon.

Our previous studies dealt with identifying banks which are still operating but are already very likely to be hiding their NNW from the Bank of Russia (Mamonov, 2017). We found that between 300 and 400 banks were de facto bankrupt in the middle of 2016, while their total NNW may have ranged from $3.6 \%$ to $6.8 \%$ of GDP. Mamonov (2018a) further showed that the supply of loans to the economy would have expanded at a faster pace without those banks. These banks were also found to slow the growth of long-term loans to the economy by replacing them with short-term loans, for which provisions are allowed to be released more often, thus, creating a semblance of periodic recovery in profitability (or at least a reduction in losses). Finally, Mamonov (2018b) found that the Bank of Russia's tough supervision policy produced an indirect positive effect, making a part of fragile banks cleanse their balance sheets of dubious transactions without waiting for the Bank of Russia's intervention and a licence revocation. At the same time, Mamonov (2019) showed that the regulator's interest rate policy, despite its effectiveness and predictability (Drobyshevsky et al., 2017), could have had a riskprovoking effect for a number of banks remaining in the system, since it increased both the probability of detection and size of NNW (a standard adverse selection effect under higher interest rates).

This paper continues to explore the phenomenon of NNW at Russian banks, following up our previous studies (Mamonov, 2017, 2018a, 2018b, 2019), and addresses an empirical issue of whether imbalances in the maturity structure of banking transactions can predict the detection of NNW at banks.

To answer this question, a new type of an explanatory variable is added to the Heckman selection model used in our previous studies: that of banks' positive negative imbalances in the maturity structure of these transactions (less than one year, 1-3 years, and over 3 years). There is a total of three transaction types on

\footnotetext{
${ }^{5}$ The issue of relationships of such cycles with classical credit cycles introduced in the seminal paper by Kiyotaki and Moore (1997), and the credit cycle mechanism based on economic agents' diagnostic mechanisms introduced recently in Bordalo et al. (2018), is interesting in itself and also calls for a separate study. Also, an issue of the relationship between the above-mentioned cyclicity of banking system development and the stages of Russia's movement to the cluster of countries with a better developed financial sector (for details of this transition see Stolbov et al., 2018) merits special consideration.
} 
the asset side and as many on the liabilities side. Imbalances for an individual transaction type are examined with respect to just one economic agent type. In other words, this paper does not explore the distribution of banks' funding sources for loans to particular types of economic agents. This requires a number of important restrictive assumptions regarding the weights for the funds obtained from various economic agents, which an individual bank then uses in funding loans to a particular type of economic agents. These important issues will be subjects of further studies.

This study is not based on a rigorous assumption that loans to, for example, households are only funded by accounts/deposits. Rather, a question is posed whether an imbalance observed between these two transaction types is able to send a signal about the approaching detection of NNW. Moreover, this study is corroborated by a number of other papers (Mian et al., 2013; Mian et al., 2017; Beck et al., 2012; Mamonov, 2018c), which find that households' ability to control their risks is much more limited than that of firms. ${ }^{6}$

These issues have not yet been dealt with in previous studies on either Russia or any other countries. Indeed, other studies regarding Russian banks have not so far touched upon the subject of negative capital; only Zhivaikina and Peresetsky (2017) focus their analysis of bank bankruptcies on the 2012-2016 period, which saw the most extensive effort by the Bank of Russia to detect banks' NNW. The question about what determines the NNW magnitude if detected remains unaddressed. Karminsky and Rybalka (2018) construct bankruptcy models factoring in NNW, but for non-financial companies rather than for banks.

Selection models of Russian banks' NNW, which this study develops in the context of currency and maturity structure imbalances of banking transactions, can be used in prudential regulation as a system of early identification of fragile banks and their removal from the market.

The paper is structured as follows. Section 2 discusses the methodology of Heckman selection models applied to an analysis of banks' NNW. Section 3 describes sources of data for Russian banks and analyses descriptive statistics of positive and negative imbalances in banks' transactions with various economic agents. Section 4 presents the results of regression analysis and an out-of-sample forecast of banks' NNW in the time interval between mid-2017 and mid-2019. Section 5 concludes.

\footnotetext{
6 This explains why in practice household term deposits usually bear higher interest rates - banks (partially) compensate households for their limited ability to control their risks by providing a premium, which results in lower rates on corporate deposits. A similar distribution of interest rates should (in an ideal world) also translate into banks' assets. In other words, household loans should be more expensive than corporate ones. The latter is also usually observed in practice, at least in average terms.
} 


\section{Methodology: Heckman cross-sectional selection models}

To estimate the ability of the term structure imbalances in banking transactions to predict the detection of banks' NNW, Heckman cross-sectional selection models are used (Heckman, 1979), just as in our previous studies (Mamonov, 2017, 2018a, 2018b, 2019). These models are different from standard regression models measuring particular indicators (for example, linear models estimated using OLS or IV-2SLS) in that, first, they adjust the estimates of coefficients in modelling the value of the indicator in question, factoring in the sample selection bias. Second, selection models form our perceptions of the probability that the object will be included in an incomplete sample (in our case, the inclusion of a bank that is still in operation in the sample of banks whose NNW has already been detected). At the same time, typical selection models are not free from drawbacks limiting their application in academic research. Their main drawback is the rigidity of the assumption about the functional form of error distribution in the model. A joint normal distribution is usually assumed for the error terms in the equation estimating the value of the indicator in question and in the equation describing the probability of an object being attributed to an object class with observed values of this indicator. This study makes an attempt to partially loosen this assumption by constructing conclusions about the significance of coefficients based on bootstrapping their standard errors.

The Heckman selection model examined in this study is made up of a selection equation and an equation of size. The former estimates the probability of the detection of NNW upon an increase in an imbalance of type $k(k=1,2,3)$ in transactions with economic agents from group $j(j=1,2)$; the latter measures the NNW size if it emerges. Therefore, two groups of economic agents are studied: households $(j=1)$ and firms $(j=2)$, with three imbalance types analysed - for transactions with maturities of less than one year $(k=1)$, from 1 to 3 years $(k=2)$, and over 3 years $(k=3)$. This forms a set of 6 versions of Heckman models. Each of the 6 versions is then split into two: the first one estimates the role of a positive imbalance, and the second estimates - that of a negative imbalance. A positive imbalance means a situation where the share of $k$ type loans to agent $j$ in a bank's assets exceeds the share of accounts and deposits of the same $k$ type, obtained from agents of the same $j$ type; a negative imbalance implies the opposite situation. As a result, $6^{*} 2=12$ versions of the Heckman model are estimated. A typical model can be given by:

$$
\begin{aligned}
\operatorname{Pr}\left\{N N W_{i t}>0\right\}=\Phi\left\{\alpha_{1}+\xi_{1}\right. & M A T U R I T Y_{i t-1}^{(k)} \\
& \left.+\sum_{l=1}^{L} \varphi_{1, l} \cdot \operatorname{MICRO}_{l, i t-1}+\delta \cdot \ln T A_{i t}\right\}
\end{aligned}
$$




$$
\begin{aligned}
\frac{N N W_{i t}}{\operatorname{Assets}_{i t-1}}=\alpha_{2}+\xi_{2} \text { MATURITY } & \text { Rit-1 } \\
& +\sum_{l=1}^{L} \varphi_{2, l} \cdot \operatorname{MICRO}_{l, i t-1}+\psi \lambda_{i t}+\varepsilon_{2, i t},
\end{aligned}
$$

where $i$ is the index of a bank belonging to either a group that went bankrupt in the 2007-2019 period or those which continued to operate as of the end of the sample period (the end of 2019Q2). Accordingly, $t$ is either a quarter in which bank $i$ faced a licence revocation $(t=2007 Q 1 . .2019 Q 2)$ or (for surviving banks) the last quarter in our sample $(t=2019 Q 2) . N N W_{i t}(N N W)$ is a dependent variable: the magnitude of NNW (a negative difference between total assets and total liabilities after an inspection by provisional administration appointed by the Bank of Russia, billion rubles, Mamonov (2017); the measure is further converted to a relative number for simplicity of interpretation. Assets $s_{i t-1}$ is total assets on a bank's balance sheet at a time preceding time $t . \operatorname{Pr}\left\{N N W_{i t}>0\right\}$ is the probability of detecting NNW at bank $i$ at time $t$. $\Phi\{\cdot\}$ is the standard normal distribution function. MATURITY $Y_{i t-1}$ is a key explanatory variable reflecting an imbalance, positive or negative, in the term structure of banking transactions. $M I C R O_{l, i t-1}$ is $l$-th control variable belonging to banking factors reflecting the parameters or effectiveness of a bank's business model. Just as in Mamonov (2019), the list of control variables is in line with the consensus set from the previous studies: the balance of equity (a ratio of capital to total assets), liquid assets (cash in vault and the balances of correspondent accounts with the Bank of Russia, $\%$ of total assets), non-performing loans (\% of total loans), return on equity (ROE), change in assets (a rise in total assets over a rolling year), see, e.g. Schaeck (2008); Brown and Dinc (2011); DeYoung and Torna (2013); Bennett and Unal (2014); Kang et al. (2015); Cole and White (2017); Kostrov and Mamonov (2019). $\lambda_{i t}$ is Heckman's lambda, a variable calculated as a ratio of the function of normal distribution density in the linear combination of selection equation (1) regressors to the value of the distribution function in this combination. $\varepsilon_{1, i t}$ and $\varepsilon_{2, i t}$ are regression errors in selection equation (1) and the equation of size (2), respectively. As in previous studies, a bank size is added to the selection equation. Size affects the probability of selection (the Too Big To Fail effect, O'Hara and Shaw, 1990) and influences the absolute NNW magnitude $\left(N N W_{i t}\right)$ but has no effect on the relative NNW magnitude $\left(N N W_{i t} /\right.$ Assets $\left._{i t-1}\right)$. The absolute NNW magnitude depends on a bank's size, while relative magnitude depends on the scale of balance sheet fraud.

Positive and negative imbalances based on the variable MATURITY ${ }_{i t-1}^{(k)}$ are in turn defined as either a positive (3) or negative (4) difference between the relevant types of loans $\left(\operatorname{LOANS}_{i t-1}^{(k)}\right)$ and accounts and deposits $\left(\right.$ DEPOSITS $\left._{i t-1}^{(k)}\right)$ : 
MATURITY $_{i t-1}^{(k)}=$ POSITIVE IMBALANCE $E_{i t-1}^{(k)}$

$= \begin{cases}\frac{\operatorname{LOANS}_{i t-1}^{(k)}-\text { DEPOSITS }_{i t-1}^{(k)}}{\operatorname{Assets}_{i t-1}^{(k)}}, & \text { if } \frac{\operatorname{LOANS}_{i t-1}^{(k)}-\text { DEPOSITS }_{i t-1}^{(k)}}{\operatorname{Assets}_{i t-1}^{(k)}}>0 ; \\ 0, & \text { if otherwise, }\end{cases}$

or

$\operatorname{MATURITY}_{i t-1}^{(k)}=$ NEGATIVE IMBALANCE $E_{i t-1}^{(k)}$

$= \begin{cases}\frac{\operatorname{LOANS}_{i t-1}^{(k)}-\text { DEPOSITS }_{i t-1}^{(k)}}{\operatorname{Assets}_{i t-1}^{(k)}}, & \text { if } \frac{\text { LOANS }_{i t-1}^{(k)}-\text { DEPOSITS }_{i t-1}^{(k)}}{\operatorname{Assets}_{i t-1}^{(k)}}<0 ; \\ 0, & \text { if otherwise. }\end{cases}$

Accordingly, the null-hypothesis tested in this study is that an increase (in absolute value) in a positive or negative imbalance can serve as an informative harbinger of NNW detection and its subsequent growth. In terms of the above symbols, this is equivalent to the following conditions:

First: $\xi_{1}>0$ and $\xi_{2}>0$ in equations of selection (1) and size (2), respectively, in the case of a positive imbalance.

Second: $\xi_{1}<0$ and $\xi_{2}<0$ in equations of selection (1) and size (2), respectively, in the case of a negative imbalance.

The division into positive and negative imbalances is necessary for two reasons. The first one (technical) is that otherwise only a net effect would be captured as a resultant of positive and negative imbalance. The second (substantive) reason is that an increase in a positive imbalance may reflect some types of risks, whereas a rise in a negative imbalance can represent other types of risks, and there would be no distinction between them if no division is done. For instance, an increase in a positive imbalance in the maturity structure of transactions may reflect the increase of liquidity risks - difficulty in paying interest on (shorter) deposits because of (longer) loans. A rise in a negative imbalance, on the other hand, may represent the escalation of market risks - a shortfall of interest income earned from (shorter) loans given the available (longer) deposits; longer loans usually bear higher interest than shorter ones, reflecting a premium for a greater uncertainty over longer horizons. ${ }^{7}$

Finally, the model captures a bias resulting from the incompleteness of the sample if there is a statistically significant correlation between regression errors $\varepsilon_{1, i t}$ and $\varepsilon_{2, i t}$. If this correlation is statistically significant, this will be reflected in the statistical significance of coefficient $\psi$ before the Heckman's lambda $\lambda_{i t}$ '

\footnotetext{
${ }^{7}$ This statement is, of course, not true in the case of an inverted yield curve and should, therefore, be treated with caution. During the time interval under analysis, the yield curve was inverted in Russia. The author thanks the anonymous reviewer for this comment.
} 
and the model will adjust the estimates of other coefficients in the equation of size (2). If, however, the correlation between regression errors shows to be nonsignificant, Heckman's lambda will also be non-significant, and the estimates of the size equation will be qualitatively similar to their OLS analogues.

Note that we estimate equations (1) and (2) sequentially rather than simultaneously - as part of the two-step procedure proposed in Heckman (1979). This procedure has its merits and flaws. The former is a partial loosening of the assumption about joint normal distribution of the regression errors in equations (1) and (2). The latter is the lower significance of the resulting coefficients' estimates in equations (1) and (2), which, in addition, can be liable to a fairly strong multicollinearity (Puhani, 2000). For this reason, we also conduct additional series of estimations of equations (1) and (2), as part of which we simultaneously estimate these equations using the maximum likelihood method. This addresses the multilinearity problem but further increases our dependence on the assumption about the normality of regression errors.

\section{Panel data based on banks' balance sheets}

All the data on the explanatory variables of the equations of selection (1) and size (2) required for analysis were obtained from the trial balance sheets (Form 101) published on a monthly basis for almost all Russian banks on the Bank of Russia's official website since $2004 .^{8}$ This balance sheet data provides information on the structure of each bank's assets and liabilities, including a breakdown by currency and maturity of banking transactions with various economic agents. Dependent variables were constructed using the Bank of Russia Bulletin, providing data on the structure of banks' assets and liabilities after their banking licences were revoked (since 2008). ${ }^{9}$ Negative difference between the remaining assets and liabilities reflects the magnitude of banks' NNW. All the data was collected for the period until mid-2019. Further analysis excludes the largest partially government-owned banks. In view of data omissions for various explanatory variables, a total of 409 banks with NNW detected in the period from 2008 through mid-2019 and 1,121 banks operating in the same period were finally available for analysis. The sample contained 421 operating banks as of mid-2019.

Table 1 consists of two panels: the first one provides information on positive and negative imbalances of banking transactions with households, and the second one contains imbalances in transactions with businesses. Columns 2-5 present this information for the subgroup of operating banks, and columns 6-9 provide data for the failed banks with NNW detected.

\footnotetext{
${ }^{8}$ See http://www.cbr.ru/banking_sector/otchetnost-kreditnykh-organizaciy/

${ }^{9}$ See http://www.cbr.ru/about_br/publ/vestnik/year/2018/
} 
Table 1. Descriptive statistics of positive and negative imbalances in transactions with households and businesses: failed banks with detected NNW versus operating banks

\begin{tabular}{|c|c|c|c|c|c|c|c|c|}
\hline \multirow[b]{2}{*}{ Variable } & \multicolumn{4}{|c|}{ Operating banks: } & \multicolumn{4}{|c|}{ Failed banks: } \\
\hline & Average & $\begin{array}{l}\text { Std. } \\
\text { dev. }\end{array}$ & Minimum & Maximum & Average & $\begin{array}{l}\text { Std. } \\
\text { dev. }\end{array}$ & Minimum & Maximum \\
\hline \multicolumn{9}{|c|}{ Panel 1: imbalances in transactions with households, \% of banks' total assets } \\
\hline $\begin{array}{l}\text { 1. Loans with maturities of } \\
\text { less than } 1 \text { year - accounts } \\
\text { and deposits with maturities } \\
\text { of less than } 1 \text { year }\end{array}$ & -8.5 & 11.9 & -70.1 & 78.7 & -10.0 & 12.7 & -67.9 & 42.4 \\
\hline positive difference & 0.7 & 4.0 & 0.0 & 78.7 & 0.6 & 2.9 & 0.0 & 42.4 \\
\hline negative difference & -9.2 & 10.6 & -70.1 & 0.0 & -10.6 & 11.8 & -67.9 & 0.0 \\
\hline $\begin{array}{l}\text { 2. 1-3-year loans }-1-3- \\
\text { year accounts and deposits }\end{array}$ & -9.1 & 15.8 & -77.5 & 59.8 & -21.1 & 21.6 & -78.2 & 55.7 \\
\hline positive difference & 1.6 & 5.0 & 0.0 & 59.8 & 0.9 & 4.5 & 0.0 & 55.7 \\
\hline negative difference & -10.7 & 13.9 & -77.5 & 0.0 & -22.0 & 20.1 & -78.2 & 0.0 \\
\hline $\begin{array}{l}\text { 3. Over-3-year loans - } \\
\text { over-3-year accounts } \\
\text { and deposits }\end{array}$ & 4.4 & 10.6 & -53.7 & 90.1 & 2.5 & 9.3 & -54.6 & 36.6 \\
\hline positive difference & 5.3 & 9.5 & 0.0 & 90.1 & 4.0 & 6.8 & 0.0 & 36.6 \\
\hline negative difference & -0.8 & 3.5 & -53.7 & 0.0 & -1.4 & 5.4 & -54.6 & 0.0 \\
\hline \multicolumn{9}{|c|}{ Panel 2: imbalances in transactions with businesses, $\%$ of banks' total assets } \\
\hline $\begin{array}{l}\text { 1. Loans with maturities of } \\
\text { less than } 1 \text { year - accounts } \\
\text { and deposits with maturities } \\
\text { of less than } 1 \text { year }\end{array}$ & 11.8 & 15.7 & -83.2 & 96.6 & 18.4 & 19.8 & -49.5 & 90.9 \\
\hline positive difference & 12.8 & 14.3 & 0.0 & 96.6 & 18.7 & 19.4 & 0.0 & 90.9 \\
\hline negative difference & -0.9 & 4.5 & -83.2 & 0.0 & -0.3 & 2.6 & -49.5 & 0.0 \\
\hline $\begin{array}{l}\text { 2. 1-3-year loans - 1-3-year } \\
\text { accounts and deposits }\end{array}$ & 8.7 & 10.4 & -60.7 & 89.4 & 13.7 & 14.9 & -55.1 & 76.9 \\
\hline positive difference & 9.1 & 9.8 & 0.0 & 89.4 & 14.1 & 14.2 & 0.0 & 76.9 \\
\hline negative difference & -0.3 & 2.2 & -60.7 & 0.0 & -0.3 & 3.1 & -55.1 & 0.0 \\
\hline $\begin{array}{l}\text { 3. Over-3-year loans - } \\
\text { over-3-year accounts } \\
\text { and deposits }\end{array}$ & 2.4 & 7.9 & -81.9 & 59.7 & 2.2 & 10.4 & -60.8 & 54.3 \\
\hline positive difference & 3.4 & 6.0 & 0.0 & 59.7 & 4.0 & 7.9 & 0.0 & 54.3 \\
\hline negative difference & -1.1 & 4.4 & -81.9 & 0.0 & -1.9 & 5.5 & -60.8 & 0.0 \\
\hline
\end{tabular}

Note: the sample of operating banks is comprised of all banks with valid banking licences for the period from the start of 2008 through mid-2019 (38,495 observations in the bank-quarter format). The sample of failed banks is comprised of all banks with banking licences revoked following the NNW detection by the Bank of Russia over the same period (409 observations in the bank-quarter format). Std. dev. - standard deviation.

The analysis of descriptive statistics of banking transaction imbalances suggests the following conclusions on what indicators can be significant in predicting banks' NNW.

First, noteworthy is an imbalance between household loans and accounts/ deposits with a maturity of 1-3 years: the average imbalance is negative for both failed and operating banks, but failed banks' figure is twice as high. At least 1/5 
of failed banks' assets is covered by this imbalance. It should be emphasised that this is average difference, whereas the minimal values of negative imbalances show no visible difference between the two groups of banks for these two transaction types. ${ }^{10}$ By contrast, transactions such as loans and deposits with a maturity of less than 1 year (short-term transactions, for instance, a part of consumer loans, credit cards, etc.) or over 3 years (long-term transactions, such as mortgage loans) ${ }^{11}$ show no substantial differences between the above groups of banks.

Second, the analysis of data from Panel 2 suggests, first, that corporate lending is 'imbalanced' with respect to accounts/deposits, and, second, that such imbalances may be formed primarily by short-term and medium-term loans (which indirectly confirms the conclusions of one of our previous studies, Mamonov, 2018a) rather than long-term loans.

Table 2 has the following structure. Panel 1 presents information on operating banks; Panel 2 provides data on failed banks. The analysis of descriptive statistics suggests the following conclusions. First, NNW size at failed banks is quite substantial even in average terms: about $1 / 3$ of such banks' assets were effectively non-earning ones (i.e., not earning interest income or any other income type). In extreme cases, the relative NNW magnitude reached almost $100 \%$ of total assets. We do not know the NNW size at operating banks. Second, the data suggests that failed banks if compared to operating ones were on average (a) less capitalised, (b) had a similar share of formally disclosed non-performing loans in total assets on their balance sheets, (c) had a lower share of liquid assets, (d) were loss-making rather than profitable, (f) growing at the same rate in annual terms.

This poses important questions for the expert and regulatory community. In particular, how can the same share of non-performing loans in total loans as at operating banks go hand in hand with being loss-making. The most likely answer is balance sheet fraud used by the failed banks for some period before their bankruptcy. This means that a closer look should be taken at banks with a low share of non-performing loans (for example, below average) and low or even negative ROE values. Similar conclusions are drawn in our previous studies. To what extent the Bank of Russia could have taken them into consideration remains an open question.

\footnotetext{
${ }^{10}$ Perhaps, the Bank of Russia should pay close attention to such operating banks - with extremely low negative imbalances in ruble-denominated medium-term transactions with households. In both cases, negative imbalances cover about $4 / 5$ of banks' total assets.

${ }^{11}$ Unfortunately, balance sheet data itself do not allow of an accurate conclusion about which specific types of loans and deposits, and their interest rates and term structures, prevail in both groups of banks. This problem can be dealt with using case studies based on internet searches for registration numbers and bank names found in balance sheet reports (it is outside the scope of this study).
} 
Table 2. Descriptive statistics of other banking variables: failed banks with NNW detected versus operating banks

\begin{tabular}{lcccc} 
Variable & Average & Std. dev. & Minimum & Maximum \\
\hline Panel 1: operating banks & & & & - \\
\hline NNW (after failure, actual), \% of total assets & - & - & - & - \\
\hline Capital (before failure) / Total assets, \% & 21.2 & 15.1 & 2.8 & 86.1 \\
\hline Non-performing loans / Total loans, \% & 5.3 & 9.6 & 0.0 & 100.0 \\
\hline Liquid assets / Total assets, \% & 18.3 & 17.3 & 0.0 & 99.9 \\
\hline $\begin{array}{l}\text { Profit for 3 months (after loan-loss provisions) / } \\
\text { Total assets, \% }\end{array}$ & 2.3 & 5.5 & -27.7 & 30.2 \\
\hline Annual change in total assets, \% & 21.1 & 40.6 & -55.6 & 305.5 \\
\hline Panel 2: failed banks with NNW & & & & \\
\hline NNW (after failure, actual), \% of total assets & 31.8 & 21.4 & 1.0 & 99.9 \\
\hline Capital (before failure) / Total assets, \% & 17.0 & 13.3 & -77.9 & 77.8 \\
\hline Non-performing loans / Total loans, \% & 5.5 & 9.0 & 0.0 & 100.0 \\
\hline Liquid assets / Total assets, \% & 13.7 & 14.7 & 0.1 & 92.6 \\
\hline $\begin{array}{l}\text { Profit for 3 months (after loan-loss provisions) / } \\
\text { Total assets, \% }\end{array}$ & -2.2 & 22.0 & -241.1 & 194.6 \\
\hline Annual change in total assets, \% & 24.1 & 71.0 & -79.6 & 587.5 \\
\hline
\end{tabular}

Note: the sample of operating banks is comprised of all banks with valid banking licences for the period from the start of 2008 to mid-2019 (38,495 observations in the bank-quarter format). The sample of failed banks is comprised of all banks with their licences revoked following the detection by the Bank of Russia of NNW over the same period (409 observations in the bank-quarter format). Std. dev. - standard deviation.

\section{Estimation results: selection models of banks' NNW with maturity imbalances}

This section presents the results of testing the hypothesis about significance of banking imbalances using Heckman cross-sectional selection models. First, estimation results for transactions with households are discussed, followed by transactions with businesses. As a reminder, three imbalance measures are considered for both types of economic agents, each split into positive and negative imbalances: (a) for transactions with a maturity of less than one year, (b) 1-3 years, and (c) more than 3 years. For the sake of interpretability of regression results, each table is followed by diagrams, presenting, first, change in both components of each imbalance indicator over time and, second, estimates of model-based values of the likelihood of detection and size of banks' NNW in four quartiles of banks' distribution by relevant imbalance measure.

\subsection{Estimation results for imbalances in short-term transactions with households}

An imbalance between loans and accounts/deposits with a maturity of less than one year. The imbalance components show a contraction in the share of loans in total assets with a maturity of less than one year, sustainable over a long-term horizon, and an abrupt increase in the share of accounts/deposits of 
similar maturities occurring in the periods of ruble depreciation (see Figures 1a and $1 \mathrm{~b}$ ), reflecting decreasing household confidence in banks during the national currency instability periods. Volatility is only notable in the second component of the imbalance.

Figure 1. Movements of the ruble exchange rate and change in banks' household loans and accounts/deposits (\% of total assets)

a) Loans with maturities of less than one year

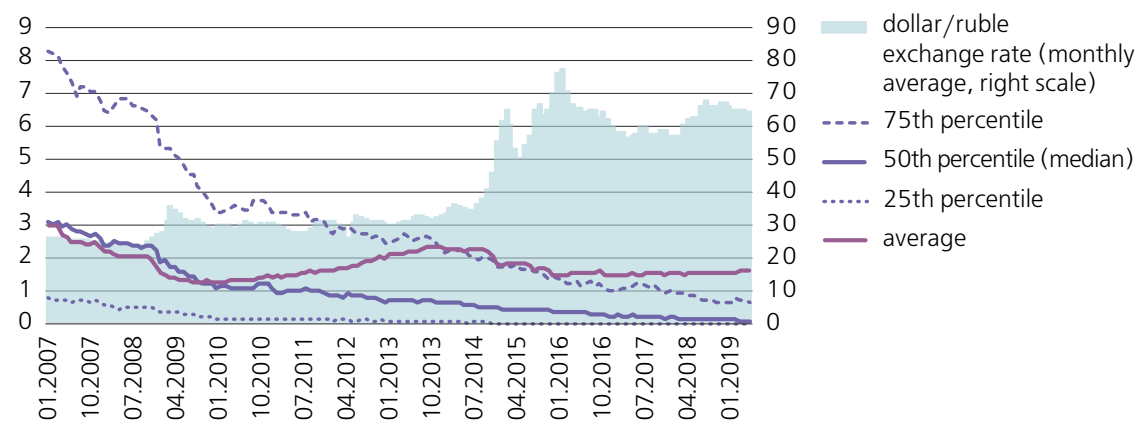

b) Accounts and deposits with maturities of less than one year

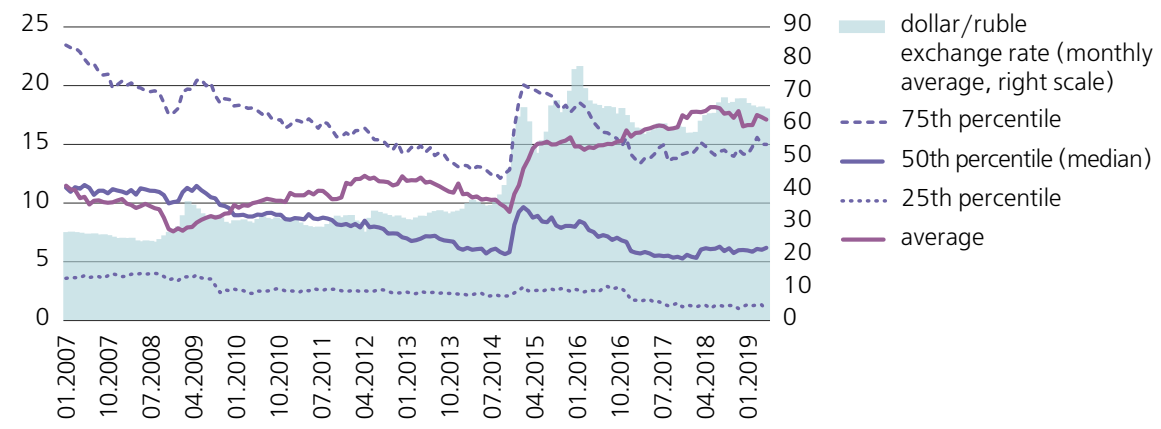

The technique for testing the hypothesis about positive and negative imbalances significance is presented below (see Table 3). Columns I and II provide the results of estimating the equation of size (2) and selection (1) in the Heckman selection model with positive imbalances of banking transactions in question, columns III and IV show those with negative imbalances. The table lines provide the results of estimating each of control variable coefficients. The hypothesis of significance of positive imbalance (positive imbalance hypothesis) will not be rejected if both coefficients of the positive imbalance variable in columns I and II show to be positive and statistically significant; the hypothesis of significance of negative imbalance (negative imbalance hypothesis) will not be rejected if both coefficients of the negative imbalance variable are found to be negative and statistically significant. 
The estimation results suggest that both hypotheses are confirmed only partially. Indeed, an increase in the positive imbalance does not produce a statistically significant growth in the relative NNW size but significantly increases the likelihood of transition from the state 'no NNW' to that 'with NNW' (see columns I and II). A negative imbalance rise in turn only increases the NNW size rather than the likelihood of its detection (see columns III and IV). ${ }^{12}$

Table 3. Results of estimating selection models of banks' NNW: the role of imbalances between household loans and accounts/deposits with maturities of less than one year

\begin{tabular}{|c|c|c|c|c|}
\hline \multirow{2}{*}{$\begin{array}{l}\text { Explanatory variables } \\
\text { (lag = } 3 \text { months) }\end{array}$} & \multicolumn{2}{|c|}{$\begin{array}{l}\text { Heckman model } \\
\text { with positive imbalance }\end{array}$} & \multicolumn{2}{|c|}{$\begin{array}{l}\text { Heckman model } \\
\text { with negative imbalance }\end{array}$} \\
\hline & Size (I) & Selection (II) & Size (III) & Selection (IV) \\
\hline Positive imbalance & $\begin{array}{l}-12.251 \\
(53.739)\end{array}$ & $\begin{array}{l}18.253^{* * *} \\
(5.563)\end{array}$ & & \\
\hline Negative imbalance & & & $\begin{array}{l}-31.815^{*} \\
(18.311)\end{array}$ & $\begin{array}{l}0.164 \\
(0.427)\end{array}$ \\
\hline Capital & $\begin{array}{l}-0.450^{* * *} \\
(0.125)\end{array}$ & $\begin{array}{l}-0.037^{\star * *} \\
(0.006)\end{array}$ & $\begin{array}{l}-0.389^{* * *} \\
(0.121)\end{array}$ & $\begin{array}{l}-0.037^{* * *} \\
(0.005)\end{array}$ \\
\hline Non-performing loans & $\begin{array}{l}-0.626 \\
(0.404)\end{array}$ & $\begin{array}{l}-0.024^{* * *} \\
(0.008)\end{array}$ & $\begin{array}{l}-0.583 \\
(0.415)\end{array}$ & $\begin{array}{l}-0.025^{* * *} \\
(0.008)\end{array}$ \\
\hline Liquid assets & $\begin{array}{l}0.276 \\
(0.309)\end{array}$ & $\begin{array}{l}-0.026^{\star * *} \\
(0.005)\end{array}$ & $\begin{array}{l}0.255 \\
(0.321)\end{array}$ & $\begin{array}{l}-0.026^{* * *} \\
(0.005)\end{array}$ \\
\hline $\mathrm{ROE}$ & $\begin{array}{l}-0.038 \\
(0.081)\end{array}$ & $\begin{array}{l}-0.017^{\star * *} \\
(0.005)\end{array}$ & $\begin{array}{l}-0.039 \\
(0.073)\end{array}$ & $\begin{array}{l}-0.017^{* * *} \\
(0.005)\end{array}$ \\
\hline Change in assets & $\begin{array}{l}0.066^{\star} \\
(0.038) \\
\end{array}$ & $\begin{array}{l}0.005^{\star * *} \\
(0.002)\end{array}$ & $\begin{array}{l}0.066^{*} \\
(0.037)\end{array}$ & $\begin{array}{l}0.005^{\star * *} \\
(0.002)\end{array}$ \\
\hline Bank size & & $\begin{array}{l}-0.432^{* * *} \\
(0.045)\end{array}$ & & $\begin{array}{l}-0.441^{* * *} \\
(0.044)\end{array}$ \\
\hline Heckman's lambda & $\begin{array}{l}11.387^{\star} \\
(6.885)\end{array}$ & & $\begin{array}{l}10.831 \\
(6.903)\end{array}$ & \\
\hline Constant & $\begin{array}{l}33.941^{* * *} \\
(3.980)\end{array}$ & $\begin{array}{l}2.091^{\star * *} \\
(0.218)\end{array}$ & $\begin{array}{l}29.685^{* * *} \\
(5.306)\end{array}$ & $\begin{array}{l}2.164^{* * *} \\
(0.216)\end{array}$ \\
\hline Number of observations, including: & & & & \\
\hline failed banks & & & & \\
\hline operating banks & & & & \\
\hline Wald statistic & & $5^{* * *}$ & & $x^{* * *}$ \\
\hline Error correlation & & & & \\
\hline
\end{tabular}

Note: Here and further on, the table presents the results of estimating the cross-sectional selection model of banks' NNW using the efficient two-step Heckman selection estimator as of the end of the sample period (1 July 2019). The dependent variable in the equation of size is the actual magnitude of a failed bank's NNW (as a percentage of the bank's total assets disclosed in balance sheet reports three months before the banking licence revocation). The dependent variable in the equation of size is a binary variable equalling 1 for banks with their licence revoked and NNW detected (in the period from 2007 to 2019) and 0 for operating banks. The explanatory variables are taken with a lag of three months from licence revocation. The standard errors of the coefficients are estimated by bootstrapping (the number of replications is 500). ${ }^{* * *},{ }^{* *}$, and ${ }^{*}-$ the coefficient estimate is significant at the 1\%-, 5\%- and 10\%-level, respectively. Parenthesized under the estimated coefficients are their robust (bootstrapped) errors.

${ }^{12}$ Here and further on, we present the results of estimating Heckman selection models obtained by a two-step procedure (see Section 2). At the same time, we also conduct estimation using the maximum likelihood method (ML). Since the results remain the same qualitatively, we do not provide ML estimates for space considerations. 
Figure 2. Size (\% of total assets) and likelihood of banks' NNW detection in the 1st-4th quartiles of distribution by value of positive (a-b) and negative (c-d) imbalance distribution in household loans and accounts/deposits with maturities of less than one year (model)

a) NNW size (model)

and positive imbalance

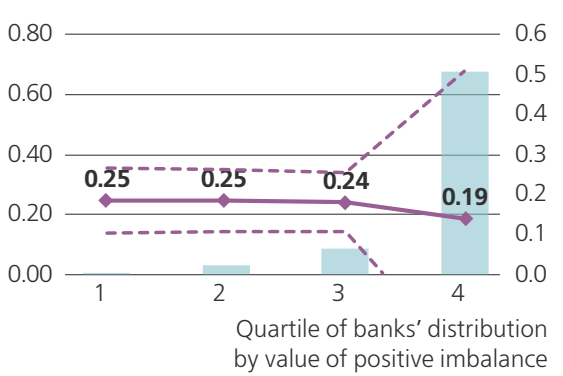

imbalance value, right scale

$\neg$ NNW magnitude (relative to banks' assets, model)

- - - 95\% confidence interval

c) NNW magnitude (model) and negative imbalance

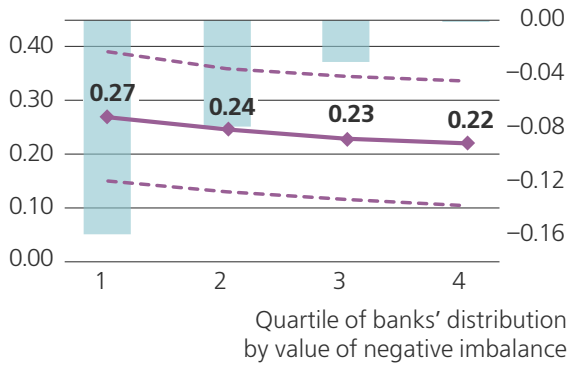

_- imbalance value, right scale

$\neg$ NNW magnitude (relative to banks' assets, model)

- - - 95\% confidence interval b) Likelihood of NNW detection (model) and positive imbalance

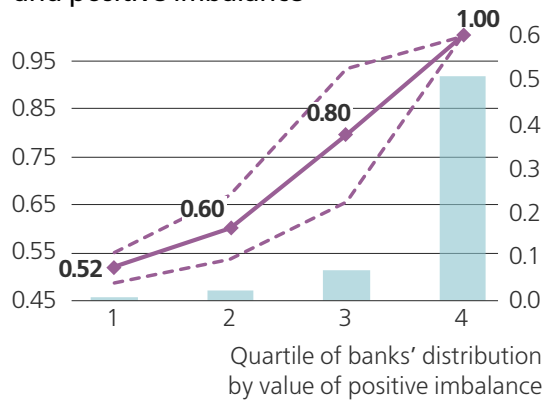

imbalance value, right scale

$\smile$ likelihood of NNW detection

- - - 95\% confidence interval

d) Likelihood of NNW detection (model) and negative imbalance

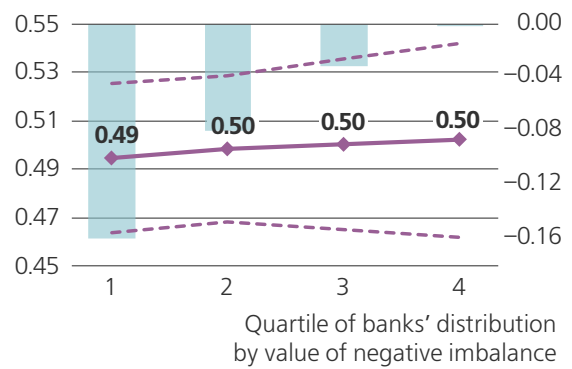

imbalance value, right scale

$\neg$ likelihood of NNW detection

- - - $95 \%$ confidence interval

The coefficients of other control variables conform the above conclusions drawn from descriptive statistics and are in line with conclusions of our previous studies (see, e.g., Mamonov, 2019). Hereon in, we will not dwell on them for space considerations.

Here and below, the results of estimating the Heckman model versions including both imbalance types are not provided for space considerations. First, the multicollinearity issue is stronger in these model versions by construction. Second, in our case, we do not discover a qualitatively different change in results as we switch to a single model (the results are available upon request). 
Also, we note that banks were deemed insolvent at different times, with the regulator's approach differing in stringency in these respective periods. This raises concern that our estimation results can be exposed to the time effect. We, however, estimate the Heckman selection model, with no time element factored in. Still, it should be noted that variation in the regulator's strictness over time was bound to be reflected in, for example, change in the capital to assets ratio on the level of individual banks in the sample, and this indicator is accounted for in all of our specifications. Variation in the regulator's strictness is therefore indirectly accounted for in our estimates.

Economic effects estimated based on the equations of selection (1) and size (2) allow formulation of a number of conclusions.

First, due to the non-significance of coefficient estimates in the models with a positive imbalance, the model values of NNW magnitude (i.e. the model values of the dependent variable in equation (2), provided that there is NNW (see Figure 2a)), are found to be uninformative in any of the quartiles of banks' positive imbalance distribution. However, with a rise in the positive imbalance corresponding to the transition from the first to the fourth quartile, the model value of likelihood increases from $52 \%$ to levels close to $100 \%$ (see Figure $2 \mathrm{~b}$ ). This is an interesting result, suggesting that it may be worthwhile for the Bank of Russia to look into the cases of a sharp rise in the positive imbalance of banks' short-term transactions with households. In such cases, loan portfolio expansion seems to rely primarily on low-quality assets.

Second, where the negative imbalance rises from the fourth to the first quartile, the NNW size varies in quite a wide confidence interval of $10-40 \%$ of banks' total assets (see Figure 2c). The model values of the likelihood of NNW detection are uninformative in the case of this transition because the relevant coefficient estimates in the selection equations are insignificant (see Figure 2d).

\subsection{Estimation results for imbalances of medium-term transactions with households}

An imbalance between loans and accounts/deposits with maturities of 1-3 years. A change in imbalance components suggests a very systemic, i.e. characteristic of most banks, contraction in the share of medium-term household loans over time (see Figure 3a), while the share of funds of the same maturity received from households remains more or less stable and very uneven across banks (Figure 3b).

Estimation rejects the positive imbalance hypothesis in medium-term transactions with households (see Table 4, columns I and II) but confirms the negative imbalance hypothesis (see columns III and IV). In particular, as the negative imbalance increases, a statistically significant rise in both the relative NNW size and the likelihood of its detection occurs. 
Figure 3. Ruble exchange rate movements and change in household loans and accounts/deposits with maturities of $1-3$ years at banks ( $\%$ of total assets)

a) Loans with maturities of 1-3 years

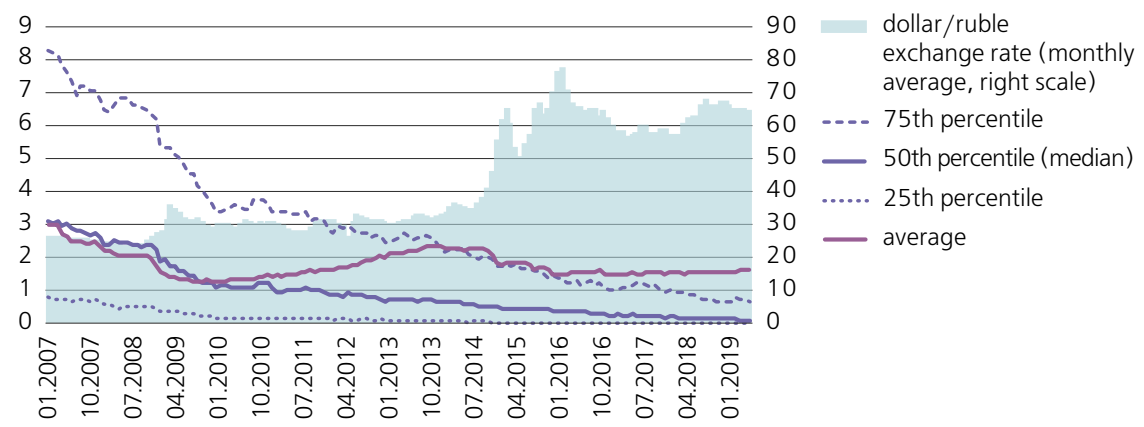

b) Accounts and deposits with maturities of 1-3 years

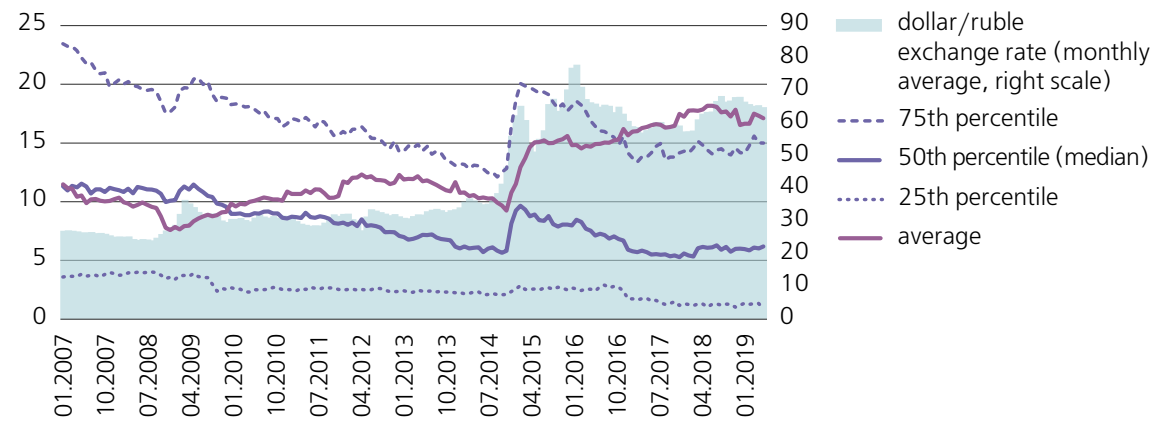

Table 4. Results of estimating selection models of banks' NNW: the role of imbalances between household loans and accounts/deposits with maturities of 1-3 years

\begin{tabular}{|c|c|c|c|c|}
\hline & \multicolumn{2}{|c|}{$\begin{array}{l}\text { Heckman model } \\
\text { with positive imbalance }\end{array}$} & \multicolumn{2}{|c|}{$\begin{array}{l}\text { Heckman model } \\
\text { with negative imbalance }\end{array}$} \\
\hline & Size (I) & Selection (II) & Size (III) & Selection (IV) \\
\hline Positive imbalance & $\begin{array}{l}-40.166 \\
(37.879)\end{array}$ & $\begin{array}{l}-0.630 \\
(1.141)\end{array}$ & & \\
\hline Negative imbalance & & & $\begin{array}{l}-27.544^{\star * *} \\
(9.408)\end{array}$ & $\begin{array}{l}-1.224^{\star * *} \\
(0.303)\end{array}$ \\
\hline Control variables & Yes & Yes & Yes & Yes \\
\hline $\begin{array}{l}\text { Number of observations, } \\
\text { including: }\end{array}$ & & & & \\
\hline failed banks & & & & \\
\hline operating banks & & & & \\
\hline Wald statistic & & & & \\
\hline Error correlation & & & & \\
\hline
\end{tabular}

Note: ${ }^{* * *},{ }^{* *}$, and ${ }^{*}$ - coefficient estimate is significant at the $1 \%$-, 5\%-, and $10 \%$-level, respectively. Parenthesised under the estimated coefficients are their robust (bootstrapped) standard errors. 
The estimation of economic effects based on the equations of selection (1) and size (2) for positive imbalances is found to be uninformative, since the estimates of the relevant coefficients are insignificant (see Figures $4 \mathrm{a}$ and $4 \mathrm{~b}$ ), while estimation based on negative imbalances suggests the following conclusions. As the negative imbalance from the fourth to the first quartiles of distribution increases, the model values of the NNW magnitude rise from $20 \%$ to $27 \%$ (although very wide confidence intervals of $10 \%-40 \%$ remain here too (see Figure $4 \mathrm{c}$ ); the model values of transition probability from the state 'no NNW' to the state 'with NNW' go up from $43 \%$ to $52 \%$, i.e. by almost 10 p.p. (see Figure 4 d). This indicator can therefore be also useful in the Bank of Russia's prudential supervision practices.

Figure 4. The size (\% of total assets) and likelihood of banks' NNW detection in the 1st-4th quartiles of distribution by value of positive (a-b) and negative ( $c-d$ ) imbalances of household loans and accounts/deposits in the maturities of 1-3 years (model)

a) NNW size (model) and positive imbalance

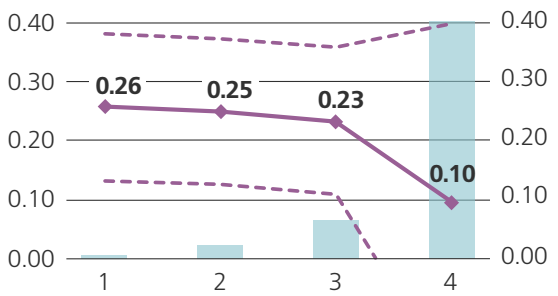

Quartile of banks' distribution by value of positive imbalance

- imbalance value, right scale

$\leadsto$ NNW magnitude (relative to banks' assets, model)

- - - 95\% confidence interval

c) NNW size (model) and negative imbalance

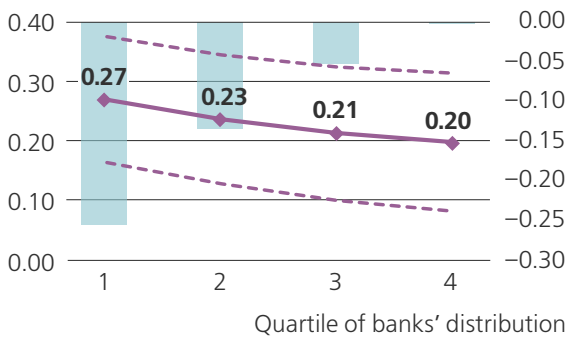
by value of negative imbalance

\footnotetext{
imbalance value, right scale

$\_$NNW magnitude (relative to banks' assets, model)

- - - 95\% confidence interval
}

b) Likelihood of NNW detection (model) and positive imbalance

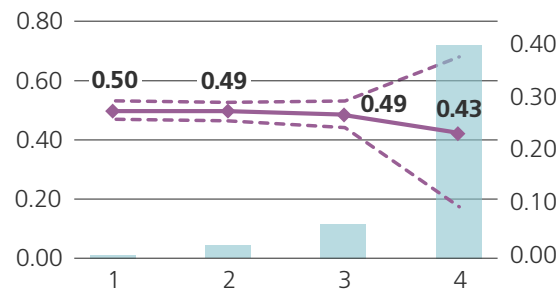

Quartile of banks' distribution by value of positive imbalance

_ imbalance value, right scale

$\leadsto \quad$ likelihood of NNW detection

- - $95 \%$ confidence interval

d) Likelihood of NNW detection (model) and negative imbalance

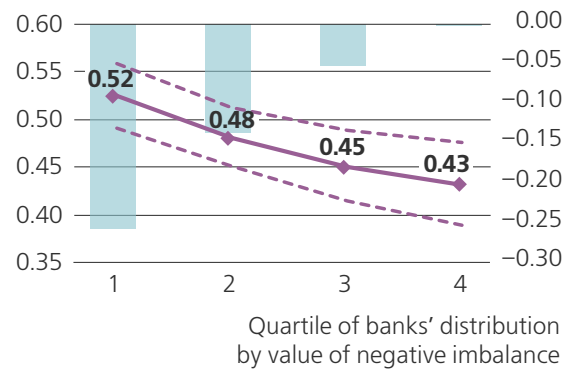

__ imbalance value, right scale

$\leadsto$ likelihood of NNW detection

- - $95 \%$ confidence interval 


\subsection{Estimation results for imbalances of long-term transactions with households}

An imbalance between loans and accounts/deposits with maturities of over three years. Change in imbalance components indicates a substantial and stable over time difference between long-term household loans and long-term accounts/ deposits: the former vary in the range of $8-12 \%$ of the banking system's total assets (see Figure $5 \mathrm{a}$ ), with the latter fluctuating in the range of just $2-3 \%$ of total liabilities (see Figure 5b). On the one hand, such differences reflect the specifics of the banking business, which aims to transform short-term liabilities into long-term assets. On the other hand, the above magnitude of the difference and its persistency point to the continuing high risks of depositors' lack of confidence in the banking system over long-term horizons. ${ }^{13}$

Figure 5. Exchange rate movements and change in household loans and accounts/deposits with maturities of over three years (\% of total assets)

a) Loans with maturities of over three years

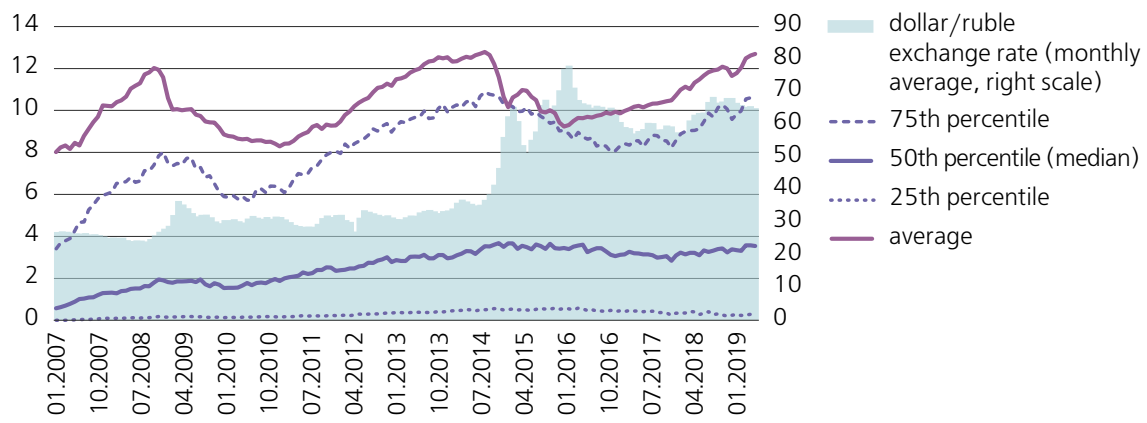

b) Accounts and deposits with maturities of over three years

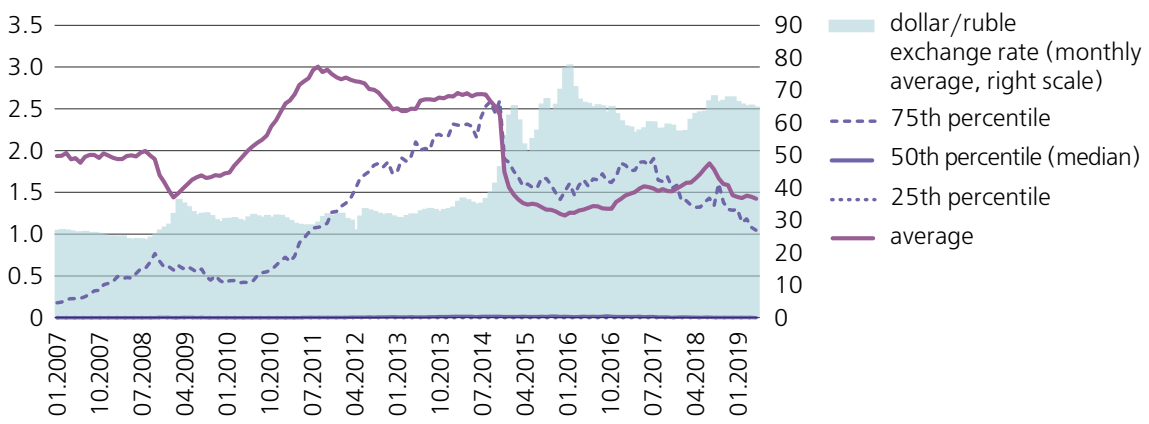

\footnotetext{
${ }^{13}$ Banks expand long-term household lending largely through mortgage and housing loans but are unable to close the gap with long-term funding from households.
} 
The estimation conducted rejects both hypotheses (see Table 5, columns I-II and III-IV). At the same time, positive imbalances in long-term transactions with households suggest an interesting conclusion: their increase is accompanied by a decline rather than growth in (a) the NNW likelihood and (b) the relative NNW size. There seem to be players in the banking system which can expand long-term household ruble lending relying on short (and inexpensive) funds not only from households but also from non-financial businesses while preserving stability against bankruptcy risks. How such banks manage their increasing liquidity risk arising from the need to service shorter liabilities is a different issue, which is out of the scope of this study.

Figure 6 . Size (\% of total assets) and likelihood of banks' NNW detection in the 1st-4th quartiles of distribution by value of positive $(a-b)$ and negative $(c-d)$ imbalances of household loans and accounts/deposits with maturities of over three years (model)

a) NNW magnitude (model) and positive imbalance

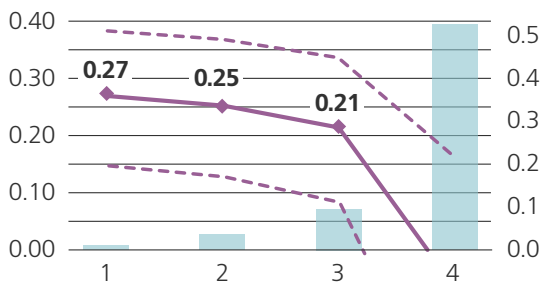

Quartile of banks' distribution by value of positive imbalance

_- imbalance value, right scale

$\leadsto$ NNW magnitude

(relative to banks' assets, model)

- - - 95\% confidence interval

c) NNW magnitude (model) and negative imbalance

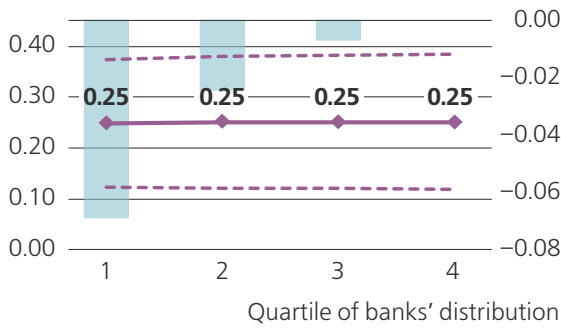
by value of negative imbalance

__ imbalance value, right scale

$\leadsto$ NNW magnitude (relative to banks' assets, model)

- - - 95\% confidence interval b) Likelihood of NNW detection (model) and positive imbalance

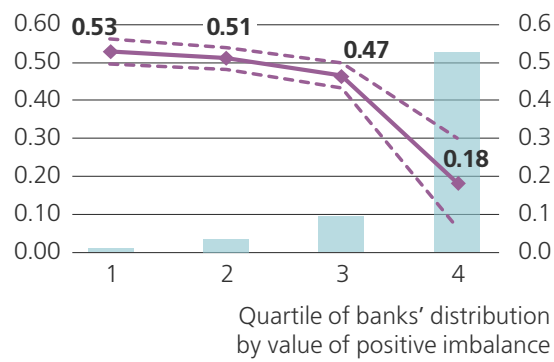

$\longrightarrow$ imbalance value, right scale
$\_$likelihood of NNW detection
$\ldots-$ - $95 \%$ confidence interval

d) Likelihood of NNW detection

(model) and negative imbalance

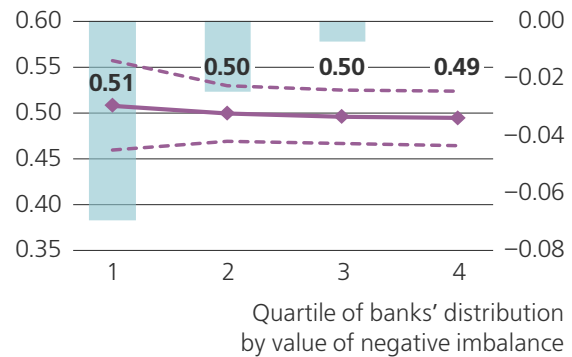

_- imbalance value, right scale

$\neg$ likelihood of NNW detection

- - - 95\% confidence interval 
Table 5. Results of estimating selection models of banks' NNW: the role of imbalances between household loans and accounts/deposits with maturities of over three years

\begin{tabular}{|c|c|c|c|c|}
\hline & \multicolumn{2}{|c|}{$\begin{array}{l}\text { Heckman model } \\
\text { with positive imbalance }\end{array}$} & \multicolumn{2}{|c|}{$\begin{array}{l}\text { Heckman model } \\
\text { with negative imbalance }\end{array}$} \\
\hline & Size (I) & Selection (II) & Size (III) & Selection (IV) \\
\hline Positive imbalance & $\begin{array}{l}-66.033^{* * *} \\
(18.575)\end{array}$ & $\begin{array}{l}-2.566^{* * *} \\
(0.621)\end{array}$ & & \\
\hline Negative imbalance & & & $\begin{array}{l}3.347 \\
(25.843)\end{array}$ & $\begin{array}{l}-0.693 \\
(1.194)\end{array}$ \\
\hline Control variables & Yes & Yes & Yes & Yes \\
\hline $\begin{array}{l}\text { Number of observations, } \\
\text { including: }\end{array}$ & \multicolumn{2}{|c|}{830} & \multicolumn{2}{|c|}{830} \\
\hline failed banks & \multicolumn{2}{|c|}{409} & \multicolumn{2}{|c|}{409} \\
\hline operating banks & \multicolumn{2}{|c|}{421} & \multicolumn{2}{|c|}{421} \\
\hline Wald statistic & \multicolumn{2}{|c|}{$35.5^{\star * *}$} & \multicolumn{2}{|c|}{$26.1^{* * *}$} \\
\hline Error correlation & \multicolumn{2}{|c|}{0.32} & \multicolumn{2}{|c|}{0.31} \\
\hline
\end{tabular}

Note: ${ }^{* * *},{ }^{* *}$, and ${ }^{\star}$ - coefficient estimate is significant at the $1 \%$-, 5\%-, and $10 \%$-level, respectively. Parenthesised under the estimated coefficients are their robust (bootstrapped) standard errors.

The estimates of economic effects obtained using the equations of selection (1) and size (2) indicate that in transition of the positive imbalance from the first to the fourth quartile, the expected NNW magnitude shrinks from $27 \%$ of total assets to zero. At the same time the likelihood of the NNW detection falls from 53\% to $18 \%$ (with a confidence interval of $5-30 \%$, see Figures $6 \mathrm{a}$ and $6 \mathrm{~b}$ ). As regards negative imbalances, the estimates of economic effects are uninformative because the relevant coefficients are statistically insignificant (see Figures $6 \mathrm{c}$ and $6 \mathrm{~d}$ ).

\subsection{Estimation results for imbalances of short-term transactions with businesses}

An imbalance between corporate loan and accounts/deposits with maturities of less than one year. Short-term corporate loans show a steady contraction over time (the first component of the imbalance under analysis, see Figure 7a), whereas short-term accounts and deposits show to being quite stable over time, although liable to a significant influence of the seasonal component, known to be related to the allocation of budget funds in the economy and the periods of corporate tax payments (the second component of the imbalance, see Figure $7 \mathrm{~b}$ ).

Unlike the previous two cases, the data we use do not provide full support for either of the two hypotheses - positive imbalance hypothesis (see Table 6, columns I and II) or negative imbalance hypothesis (see columns III and IV) imbalances of banks' short-term transactions with businesses. It is only positive imbalances that show a statistically significant increase in the likelihood of transition from the state 'no NNW' to that 'with NNW' but a statistically significant impact on the NNW magnitude itself is not found. 
Table 6. Results of estimating selection models of NNW: the role of imbalances between corporate loans and accounts/deposits with maturities of less than one year

\begin{tabular}{|c|c|c|c|c|}
\hline & \multicolumn{2}{|c|}{$\begin{array}{l}\text { Heckman model } \\
\text { with positive imbalance }\end{array}$} & \multicolumn{2}{|c|}{$\begin{array}{l}\text { Heckman model } \\
\text { with negative imbalance }\end{array}$} \\
\hline & Size (I) & Selection (II) & Size (III) & Selection (IV) \\
\hline Positive imbalance & $\begin{array}{l}4.334 \\
(10.669)\end{array}$ & $\begin{array}{l}2.020^{* * *} \\
(0.382)\end{array}$ & & \\
\hline Negative imbalance & & & $\begin{array}{l}-39.201 \\
(166.637)\end{array}$ & $\begin{array}{l}4.314 \\
(4.748)\end{array}$ \\
\hline Control variables & Yes & Yes & Yes & Yes \\
\hline $\begin{array}{l}\text { Number of observations, } \\
\text { including: }\end{array}$ & & & & \\
\hline failed banks & & & & \\
\hline operating banks & & & & \\
\hline Wald statistic & & & & \\
\hline Error correlation & & & & \\
\hline
\end{tabular}

Note: ${ }^{* *},{ }^{* *}$, and ${ }^{*}$ - coefficient estimate is significant at the $1 \%-, 5 \%$-, and $10 \%$-level, respectively. Parenthesised under the estimated coefficients are their robust (bootstrapped) standard errors.

Figure 7. Ruble exchange rate movements and change in corporate loans and accounts/deposits with maturities of less than one year ( $\%$ of total assets)

\section{a) Loans with maturities of less than one year}

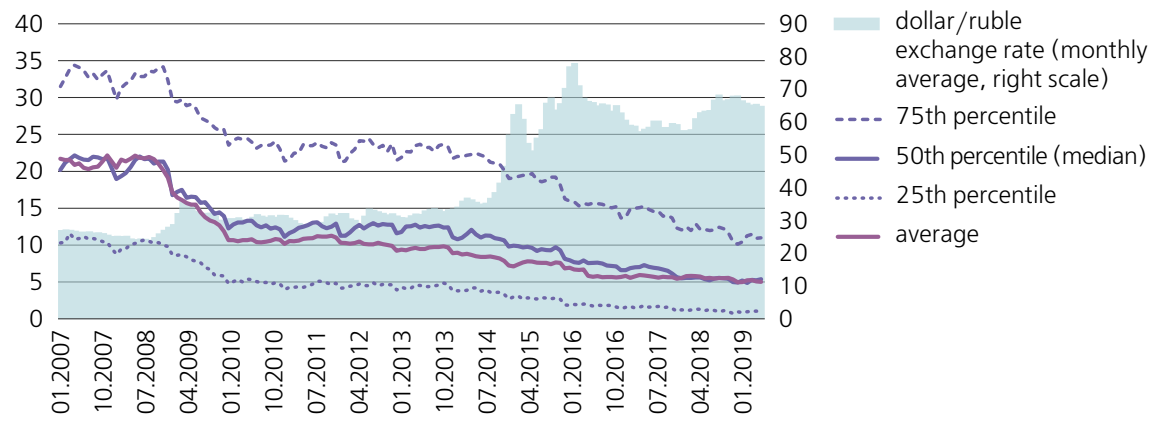

\section{b) Accounts and deposits with maturities of less than one year}

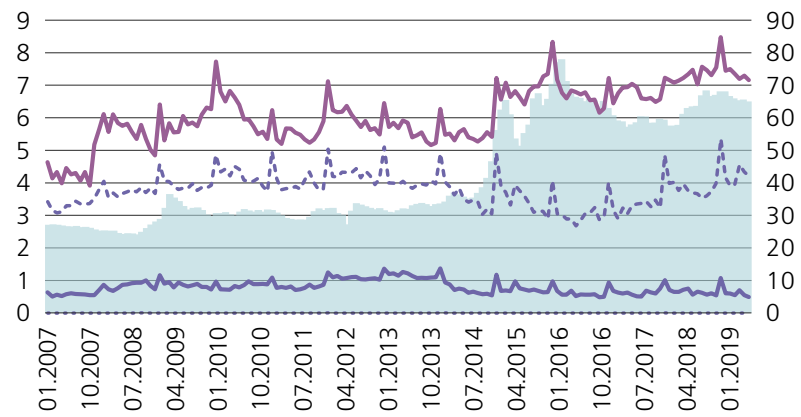

dollar/ruble exchange rate (monthly average, right scale)

75th percentile 50th percentile (median) 25th percentile average 
Figure 8. Size (\% of total assets) and likelihood of NNW detection in the 1st-4th quartiles of distribution by value of positive (a-b) and negative (c-d) imbalances of corporate loans and accounts/deposits with maturities of less than one year (model)

a) NNW magnitude (model) and positive imbalance

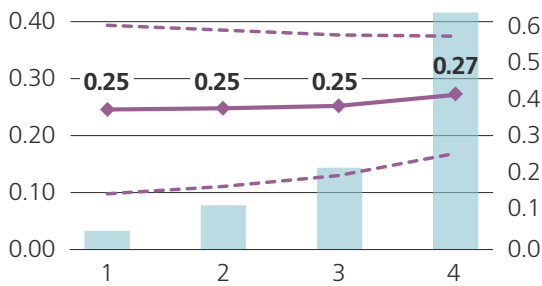

Quartile of banks' distribution by value of positive imbalance

imbalance value, right scale

$\leadsto$ NNW magnitude (relative to banks' assets, model)

- - $95 \%$ confidence interval

c) NNW magnitude (model) and negative imbalance

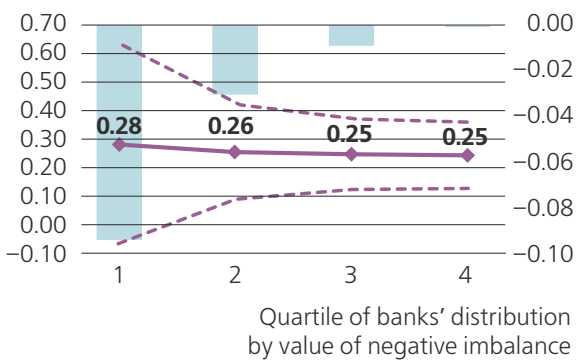

_- imbalance value, right scale

$\longrightarrow$ NNW magnitude (relative to banks' assets, model)

_. - $95 \%$ confidence interval b) Likelihood of NNW detection (model) and positive imbalance

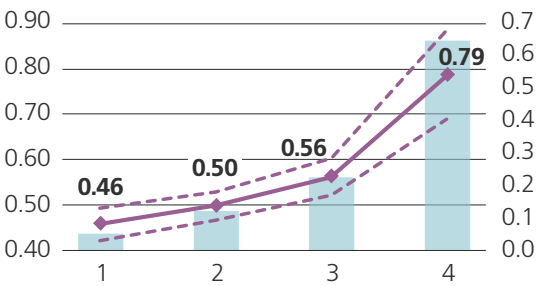

Quartile of banks' distribution by value of positive imbalance

$\longleftarrow$ imbalance value, right scale
$\_$likelihood of NNW detection
$\ldots$ _- $95 \%$ confidence interval

d) Likelihood of NNW detection (model) and negative imbalance

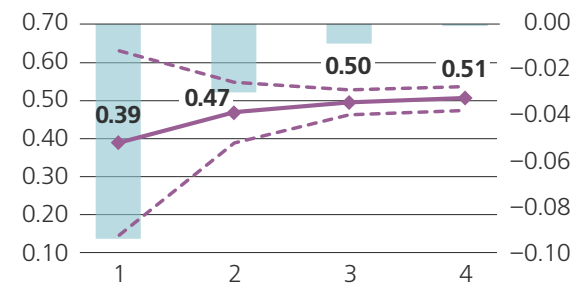

Quartile of banks' distribution by value of negative imbalance

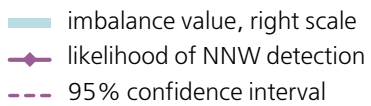

Accordingly, economic effects estimated using the equations of selection (1) and size (2) make sense only with respect to the impact of positive imbalances on the likelihood of NNW detection. In this respect, we observe an unexpectedly strong effectiveness of the indicator of positive imbalances: as it moves from the first to the fourth quartile, the model value of likelihood increases from $46 \%$ to $79 \%$, with confidence intervals being quite moderate (see Figure $8 \mathrm{~b}$ ). The other three model estimates are uninformative since the relevant coefficient estimates are insignificant (see Figures 8a, 8c, and 8d). 
Table 7. Estimates of NNW selection models: the role of imbalances between corporate loans and corporate accounts/deposits with maturities of 1-3 years

\begin{tabular}{|c|c|c|c|c|}
\hline & \multicolumn{2}{|c|}{$\begin{array}{l}\text { Heckman model } \\
\text { with positive imbalance }\end{array}$} & \multicolumn{2}{|c|}{$\begin{array}{l}\text { Heckman model } \\
\text { with negative imbalance }\end{array}$} \\
\hline & Size (I) & Selection (II) & Size (III) & Selection (IV) \\
\hline Positive imbalance & $\begin{array}{l}26.399^{* *} \\
(12.345)\end{array}$ & $\begin{array}{l}2.941^{* * *} \\
(0.496)\end{array}$ & & \\
\hline Negative imbalance & & & $\begin{array}{l}47.736 \\
(95.490)\end{array}$ & $\begin{array}{l}1.904 \\
(5.121)\end{array}$ \\
\hline Control variables & Yes & Yes & Yes & Yes \\
\hline $\begin{array}{l}\text { Number of observations, } \\
\text { including: }\end{array}$ & & & & \\
\hline failed banks & & & & \\
\hline operating banks & & & & \\
\hline Wald statistic & & & & \\
\hline Error correlation & & & & \\
\hline
\end{tabular}

Note: ${ }^{* * *},{ }^{* *}$, and ${ }^{*}$ - coefficient estimate is significant at the $1 \%$-, 5\%-, and $10 \%$-level, respectively. Parenthesised under the estimated coefficients are their robust (bootstrapped) standard errors.

Figure 9. Ruble exchange rate movements and change in corporate loans and accounts/deposits with maturities of 1-3 years at banks ( $\%$ of total assets)

a) Loans with maturities of 1-3 years

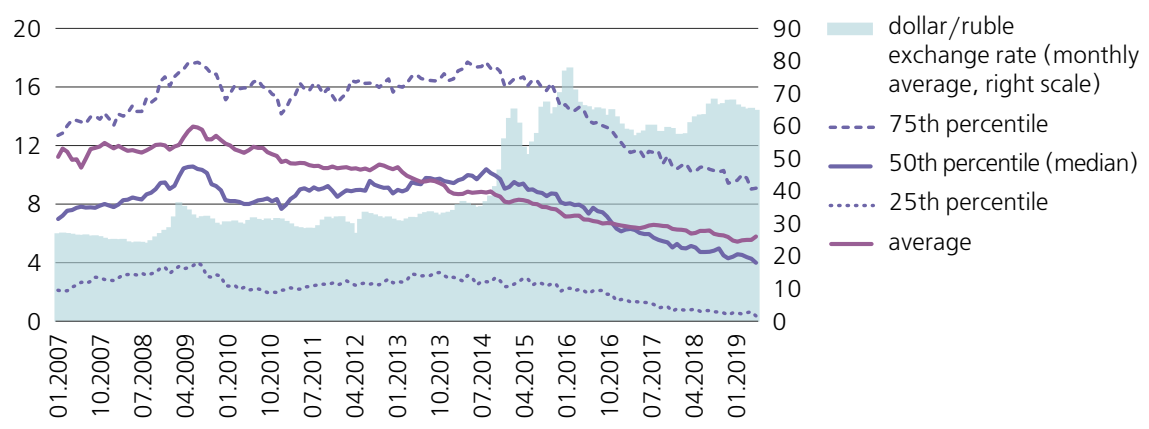

b) Accounts and deposits with maturities of 1-3 years

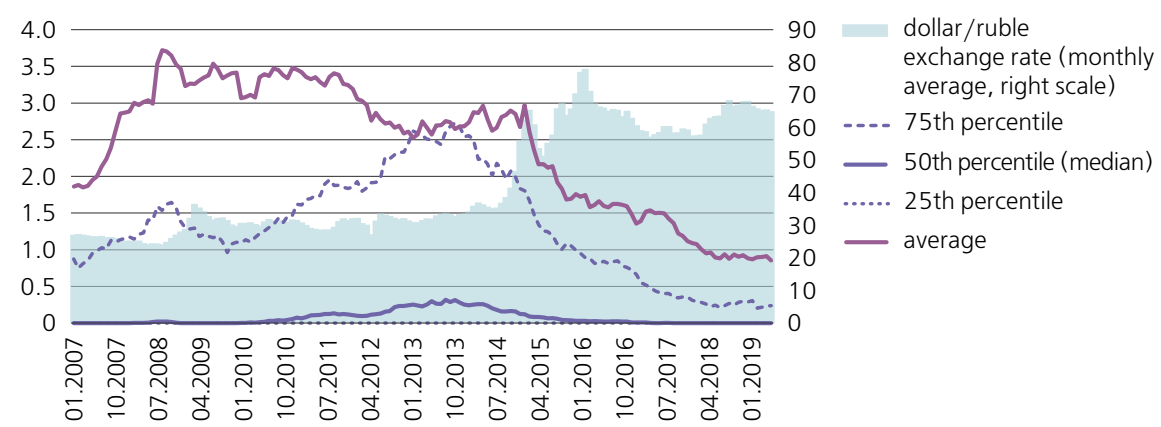


Figure 10. Size (\% of total assets) and likelihood of NNW detection in the 1st-4th quartiles of distribution by value of positive (a-b) and negative (c-d) imbalances of corporate loans and accounts/deposits with maturities of 1-3 years (model)

a) NNW magnitude (model) and positive imbalance

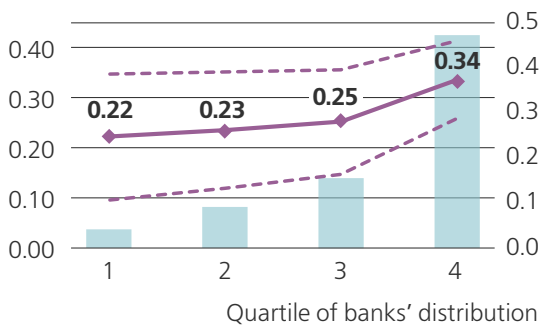

by value of positive imbalance

imbalance value, right scale

$\multimap$ NNW magnitude

(relative to banks' assets, model)

- _. $95 \%$ confidence interval

c) NNW magnitude (model)

and negative imbalance

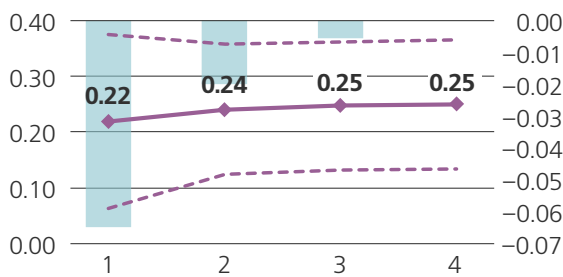

Quartile of banks' distribution

by value of negative imbalance

- imbalance value, right scale

$\leadsto$ NNW magnitude

(relative to banks' assets, model)

_. - 95\% confidence interval b) Likelihood of NNW detection (model) and positive imbalance

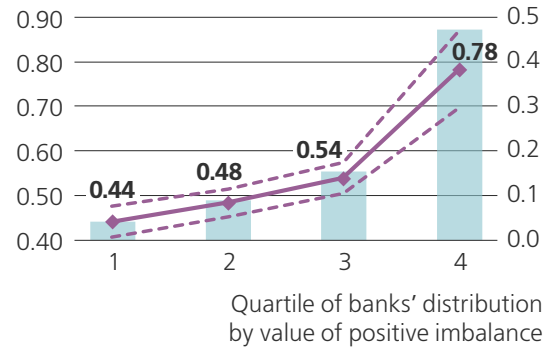

__ imbalance value, right scale

$\neg$ likelihood of NNW detection

- - $95 \%$ confidence interval

d) Likelihood of NNW detection

(model) and negative imbalance

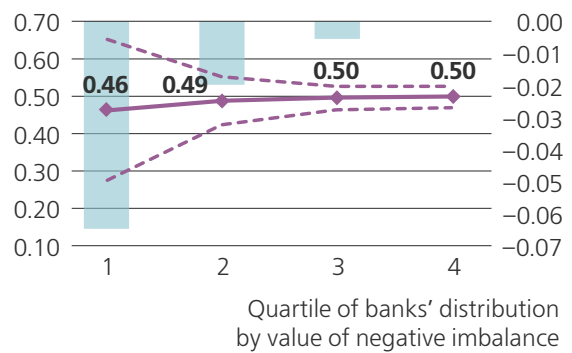

__ imbalance value, right scale

$\leadsto \quad$ likelihood of NNW detection

-.- $95 \%$ confidence interval

\subsection{Estimation results for imbalances of medium-term transactions with businesses}

An imbalance between corporate loans and accounts/deposits with maturities of 1-3 years. Both components of the imbalance show contraction over time - from the period of the 2014 recession (see Figures 9a and 9b).

The estimation provides arguments for the positive imbalance hypothesis (see Table 7, columns I and II) but does not support the negative imbalance hypothesis (see columns III and IV). In particular, at banks with higher values 
Table 8. Estimation results for selection models of banks' NNW: the role of imbalances between corporate loans and accounts/deposits with maturities of over 3 years

\begin{tabular}{|c|c|c|c|c|}
\hline & \multicolumn{2}{|c|}{$\begin{array}{l}\text { Heckman model } \\
\text { with positive imbalance }\end{array}$} & \multicolumn{2}{|c|}{$\begin{array}{l}\text { Heckman model } \\
\text { with negative imbalance }\end{array}$} \\
\hline & Size (I) & Selection (II) & Size (III) & Selection (IV) \\
\hline Positive imbalance & $\begin{array}{l}-17.004 \\
(16.448)\end{array}$ & $\begin{array}{l}0.783 \\
(0.768)\end{array}$ & & \\
\hline Negative imbalance & & & $\begin{array}{l}-14.253 \\
(45.072)\end{array}$ & $\begin{array}{l}0.088 \\
(1.142)\end{array}$ \\
\hline Control variables & Yes & Yes & Yes & Yes \\
\hline $\begin{array}{l}\text { Number of observations, } \\
\text { including: }\end{array}$ & & & & \\
\hline failed banks & & & & \\
\hline operating banks & & & & \\
\hline Wald statistic & & & & \\
\hline Error correlation & & & & \\
\hline
\end{tabular}

Note: ${ }^{* * *},{ }^{* *}$, and ${ }^{*}$ - coefficient estimate is significant at the $1 \%-, 5 \%$-, and $10 \%$-level. respectively. Parenthesised under the estimated coefficients are their robust (bootstrapped) standard errors.

Figure 11. Exchange rate movements and change in corporate loans and accounts/deposits with maturities of over three years (\% of total assets)

a) Loans with maturities of over 3 years
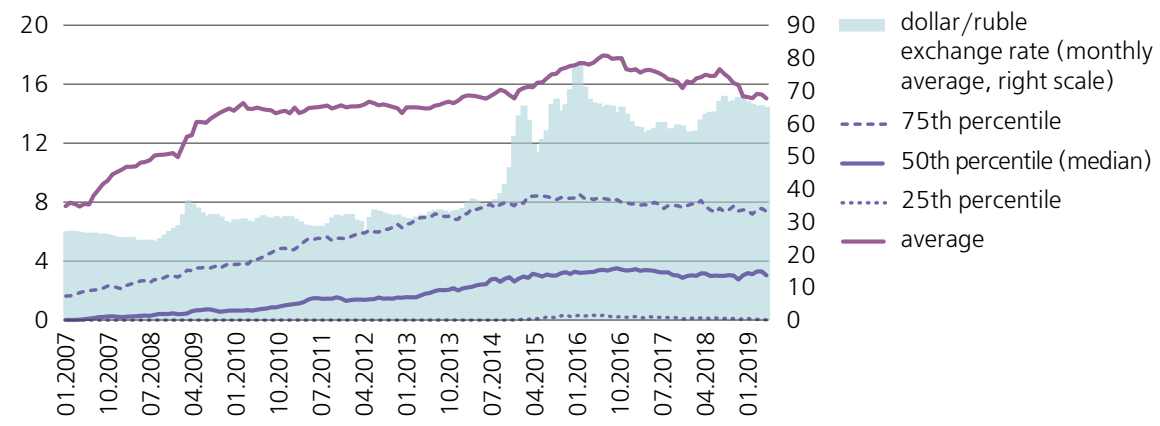

\section{b) Accounts and deposits with maturities of over three years}

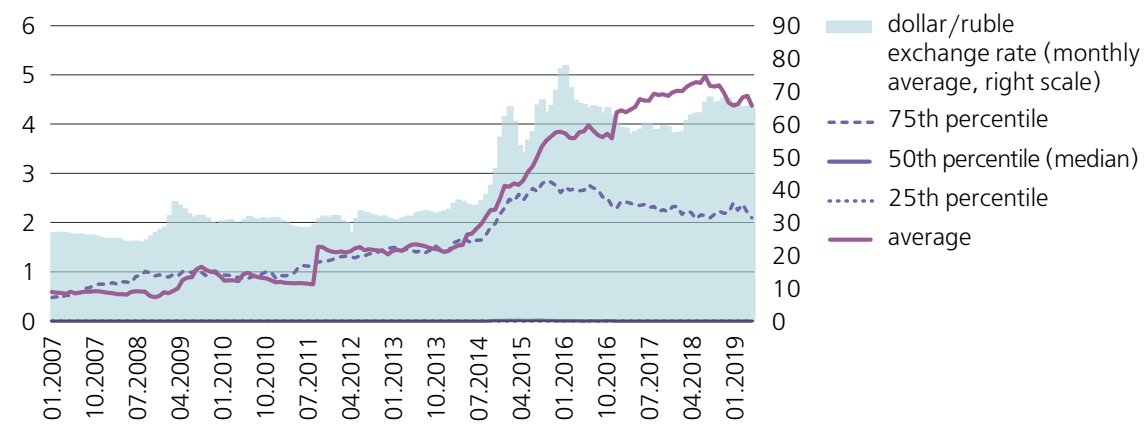


of a positive imbalance in medium-term transactions with businesses, the Heckman selection model predicts statistically higher values of both the relative size and likelihood of NNW detection, which is not the case at banks with negative imbalances. The negative imbalances indicator could also be informative for the Bank of Russia in its assessment of risks at banks in operation.

The estimation of economic effects using the equations of selection (1) and size (2) are only informative for the positive imbalance. In this case, model estimation indicates that as the distribution of banks by value of a positive imbalance moves from the first to the fourth quartile, the relative NNW magnitude increases from $22 \%$ to $34 \%$ of banks' total assets (see Figure 10a). At the same time the likelihood of NNW detection rises from $44 \%$ to $78 \%$ (see Figure 10b), and, as in the case of banks' short-term transactions with businesses, this is again quite informative from the perspective of forecasting the detection of banking system crises. In the case of negative imbalances, no statistical differences between the NNW magnitude and the likelihood of its detection are observed (see Figures 10c and 10d, respectively).

\subsection{Estimation results for imbalances of long-term transactions with businesses}

An imbalance between corporate loans and corporate accounts and deposits with maturities of over three years. Both components of the imbalance tend to rise over a long-term horizon, at least for banks that carry out such transactions despite their relatively small numbers (see Figures 11a and 11b).

It is noteworthy that regression analysis does not support either of the two hypotheses: testing both the positive imbalance hypothesis (see Table 8, columns I and II) and negative imbalance hypothesis produced statistically insignificant coefficient estimates (see Table 8, columns III and IV). Accordingly, the estimates of economic effects obtained using the equations of selection (1) and size (2) are found to be uninformative (see Figures 12a, 12b, $12 \mathrm{c}$, and $12 \mathrm{~d}$ ). Banks engaged in long-term lending to non-financial companies and confronted with a positive imbalance of the relevant transactions, seem to be able to obtain long-term funding from other economic agents. ${ }^{14}$ And, accordingly, banks that obtain a substantial part of liabilities from companies but encountering negative imbalances in transactions with them find other long-term sources of allocating these funds.

\footnotetext{
14 This is easy to check by comparing descriptive statistics computed on the entire sample and a subsample of banks with positive imbalances of long-term transactions with nonfinancial businesses. This estimation indicates that in moving from the entire sample to the subsample of interest to us, the share of longer than 3 -year household funds in total assets rises from $1.9 \%$ to $4.1 \%$.
} 
Figure 12. Size (\% of total assets) and likelihood of NNW detection in the $1 \mathrm{st}-4$ th quartiles of distribution by value of positive $(a-b)$ or negative $(c-d)$ imbalances of corporate loans and accounts/deposits with maturities of over three years (model)

a) NNW magnitude (model) and positive imbalance

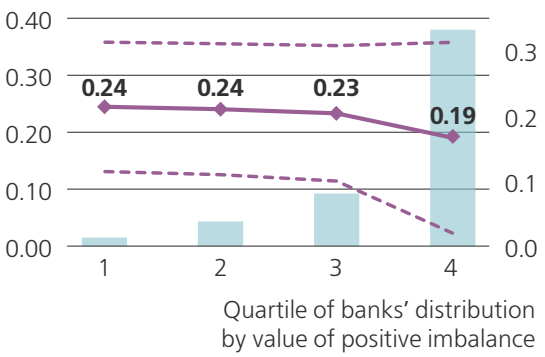

imbalance value, right scale

$\leadsto$ NNW magnitude

(relative to banks' assets, model)

- - - $95 \%$ confidence interval

c) NNW magnitude (model) and negative imbalance

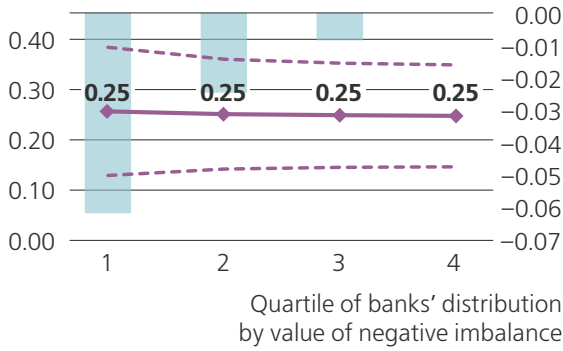

imbalance value, right scale

$\multimap$ NNW magnitude (relative to banks' assets, model)

- - - 95\% confidence interval b) Likelihood of NNW detection (model) and positive imbalance

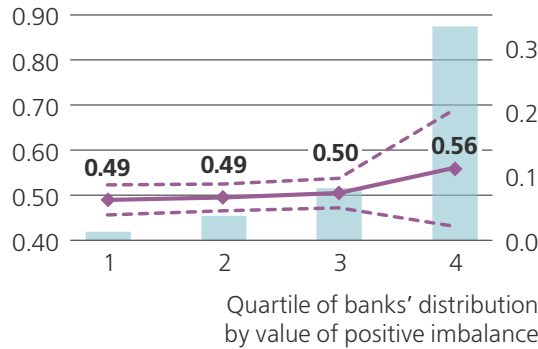

- imbalance value, right scale

$\leadsto$ likelihood of NNW detection

_. - $95 \%$ confidence interval

d) Likelihood of NNW detection

(model) and negative imbalance

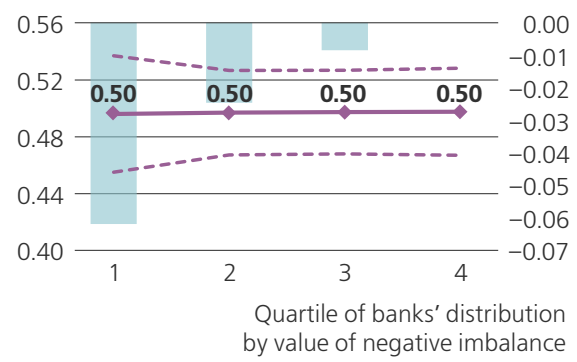

imbalance value, right scale

$\leadsto$ likelihood of NNW detection

_. - 95\% confidence interval

\subsection{Results of out-of-sample forecasts: do imbalance values help?}

Finally, we perform a procedure of an out-of-sample forecast for the number of banks with their licences withdrawn upon detection of their NNW and such banks' total NNW. To determine the role of the imbalances, the procedure of an out-of-sample forecast is performed for a baseline model containing all explanatory variables, except for imbalances, and for each of the above models including imbalance variables. Remember, the above models were estimated on the full sample, i.e., for the period until mid-2019. For the purposes of the out-ofsample recast, we first shortened the sample period by two years until mid-2017 and re-estimated all the models. According to the Bank of Russia Bulletin data, 72 banks with a total NNW of 1,018.1 billion rubles were found over these two 
years. Our procedure of out-of-sample forecasting will seek to identify such a threshold of the likelihood of NNW detection that would have allowed an utmost accuracy in forecasting the NNW detection in each of these 72 banks.

It should be emphasized that our out-of-sample forecast is conditional rather than unconditional, i.e. we will forecast the NNW size for the above 72 banks. An unconditional forecast, unlike a conditional one, would seek to determine the scale of problems at all operating banks rather than at those which were actually identified by the regulator and deemed insolvent. This important aspect was partially examined in one of our previous studies (Mamonov, 2017), but we believe that it should be studied in more depth in our future research.

That said, one drawback of our approach is that we do not account for type I and II errors, when the forecast of the model is different from the actual event. What partly justifies our approach is that, first, we do not know what the regulator's (the Bank of Russia) preferences are regarding such errors, and second, we hold the view that superfluous preparedness for crises is better than insufficient readiness for them.

In the framework of our chosen approach to forecasting, we constructed model values of dependent variables in the equations of selection and size for all banks of the reduced sample and computed Root Mean Squared Forecast Error (RMSFE) for each value of the selection likelihood threshold (from 0.01 to 1.00). RMSFE in turn has allowed obtaining a calibrated threshold of the likelihood of NNW detection. Using this threshold, we then compute how many of the actual 72 banks are captured by the model and what NNW size the model forecasts. The estimation results are summed up in Table 9.

Our estimation suggests that some imbalance variables really provide value added from the perspective of improving the quality of the out-of-sample forecast of the number of banks with NNW and its total magnitude. The baseline model, for example, predicts that 63 out of 72 banks face NNW in the period from mid2017 to mid-2019 and overestimates the average NNW size by 5 billion rubles from 14.1 billion roubles to 19.1 billion roubles. Three out of twelve models with imbalances are able to improve these results.

First, the model with positive imbalances for short-term transactions with households - the average predicted NNW magnitude is 18.9 billion roubles. It allowed a marginal improvement of just 0.2 billion rubles, which is generally of little importance.

Second, the model with negative imbalances for medium-term transactions with households - the average predicted NNW size equals 18.6 billion rubles. An improvement reaches 0.5 billion rubles here.

Third, the model with positive imbalances for short-term transactions with businesses - the average NNW size shrinks to 18.4 billion rubles. This is the largest and a more important improvement of 0.7 billion rubles.

Remarkably, the re-estimation of the model with all the three analysed imbalance variables included in the model simultaneously improves the out-of-sample forecast further. With an optimum threshold of 0.2 , this model captures 65 out of 
72 banks and forecasts a total NNW at 1,194 billion roubles, i.e., an average 18.36 billion roubles per bank. This corresponds to a 1.3 billion ruble improvement versus the baseline model.

Table 9. Results of out-of-sample forecast

\begin{tabular}{|c|c|c|c|c|}
\hline & \multirow{2}{*}{ Threshold } & \multirow{2}{*}{$\begin{array}{l}\text { Number of banks } \\
\text { with NNW }\end{array}$} & \multicolumn{2}{|c|}{ NNW size, billion rubles } \\
\hline & & & Total & Average per bank \\
\hline Actual & & 72 & 1018 & 14.1 \\
\hline Baseline model (without imbalances) & 0.13 & 63 & 1202 & 19.1 \\
\hline \multicolumn{5}{|l|}{ Models with imbalances } \\
\hline \multicolumn{5}{|l|}{ Panel 1. Households } \\
\hline \multicolumn{5}{|l|}{ Short-term transactions } \\
\hline positive imbalance & 0.13 & 63 & 1192 & 18.9 \\
\hline negative imbalance & 0.16 & 61 & 1216 & 19.9 \\
\hline \multicolumn{5}{|l|}{ Medium-term transactions } \\
\hline positive imbalance & 0.13 & 62 & 1182 & 19.1 \\
\hline negative imbalance & 0.13 & 63 & 1169 & 18.6 \\
\hline \multicolumn{5}{|l|}{ Long-term transactions } \\
\hline positive imbalance & 0.05 & 65 & 1260 & 19.4 \\
\hline negative imbalance & 0.18 & 61 & 1194 & 19.6 \\
\hline \multicolumn{5}{|l|}{ Panel 2. Non-financial businesses } \\
\hline \multicolumn{5}{|l|}{ Short-term transactions } \\
\hline positive imbalance & 0.12 & 64 & 1177 & 18.4 \\
\hline negative imbalance & 0.14 & 62 & 1227 & 19.8 \\
\hline \multicolumn{5}{|l|}{ Medium-term transactions } \\
\hline positive imbalance & 0.11 & 62 & 1206 & 19.5 \\
\hline negative imbalance & 0.13 & 62 & 1210 & 19.5 \\
\hline \multicolumn{5}{|l|}{ Long-term transactions } \\
\hline positive imbalance & 0.12 & 64 & 1217 & 19.0 \\
\hline negative imbalance & 0.16 & 62 & 1199 & 19.3 \\
\hline
\end{tabular}

It is difficult to predict NNW because it is falsified. Bearing this in mind, any improvement in the predictive power of the model, in our view, merits consideration.

\section{Conclusion}

This study conducts a microeconomic analysis of positive and negative imbalances in the maturity structure of Russian banks' transactions. The results of testing positive and negative imbalance hypotheses using Heckman selection models allow formulating a number of conclusions important from the perspective of prudential banking regulation practices.

First, imbalances do improve predictability of banks' NNW in the regression analysis of banks' NNW. The effects of change in imbalances are in many cases found to be statistically significant even taking into account literature consensus on the determinants of banks' fragility (DeYoung and Torna, 2013; Kang et al., 2015; Cole and White, 2017; Kostrov and Mamonov, 2019). Six out of the twelve Heckman model versions estimated were found to confirm positive and negative imbalance hypotheses.

Second, the division of imbalances into positive and negative ones makes sense: practically all 12 versions of estimated Heckman models identified the effects 
(opposite in sign) of positive and negative imbalances on NNW. Accordingly, without this separation carried out, there would be no distinction between different risk types, and imbalance coefficient estimates would convey very limited information.

Third, a separate analysis of banking transactions similar in currency and maturity structure but different with respect to the types of economic agents show to be opposite in sign.

And finally, our analysis identifies transactions in which imbalances have the strongest predictive power with respect to banks' NNW. Regarding the transactions with households, such indicators are the positive imbalances of short-term transactions and negative imbalances of mid-term transactions. As regards banks' transactions with businesses, our analysis reveals an important role of positive imbalances of short-term transactions in predicting banks' NNW. We believe it is worthwhile for the Bank of Russia to pay special attention to changes in these indicators when conducting its prudential supervision.

\section{References}

Beck, T., Büyükkarabacak, B., Rioja F. and Valev, N. T. (2012). Who Gets the Credit? And Does It Matter? Household vs. Firm Lending Across Countries. The B.E. Journal of Macroeconomics, 12(1), pp. 1-46.

Bennett, R. L. and Unal, H. (2014). The Effects of Resolution Methods and Industry Stress on the Loss on Assets from Bank Failures. Journal of Financial Stability, 15, pp. 18-31.

Bordalo, P., Gennaioli, N. and Shleifer, A. (2018). Diagnostic Expectations and Credit Cycles. Journal of Finance, 73(1), pp. 199-227. doi: 10.1111/jofi.12586

Brown, C. and Dinç, I. S. (2011). Too Many to Fail? Evidence of Regulatory Forbearance when the Banking Sector is Weak. Review of Financial Studies, 24(4), pp. 1378-1405.

Cole, R. and White, L. (2017). When Time Is Not on Our Side: The Costs of Regulatory Forbearance in the Closure of Insolvent Banks. Journal of Banking and Finance, 80(C), pp. 235-249. doi: 10.1016/j.jbankfin.2017.03.010

DeYoung, R. and Torna, G. (2013). Nontraditional Banking Activities and Bank Failures during the Financial Crisis. Journal of Financial Intermediation, 22(3), pp. 397-421. doi: 10.1016/j.jfi.2013.01.001

Drobyshevsky, S., Trunin, P., Bozhechkova, A., Gorunov, E. and Petrova, D. (2017). Analysis of the Bank of Russia Information Policy. Voprosy Ekonomiki, 10, pp. 88-110. [In Russian]. doi: 10.32609/0042-8736-2017-10-88-110

Heckman, J. (1979). Sample Selection Bias as a Specification Error. Econometrica, 47(1), pp. 153-161. doi: 10.2307/1912352

Kang, A., Lowery, R. and Wardlaw, M. (2015). The Cost of Closing Failed Banks: A Structural Estimation of Regulatory Incentives. Review of Financial Studies, 28(4), pp. 1060-1102. doi: 10.1093/rfs/hhu076

Karminsky, A. and Rybalka, A. (2018). NNW of Manufacturing Companies: Corporate Governance and Industry Expectations. Journal of the New Economic Association, 2(38), pp. 76-103. [In Russian]. 
Kiyotaki, N. and Moore, J. (1997). Credit Cycles. Journal of Political Economy, 105(2), pp. 211-248. doi: 10.1086/262072

Kostrov, A. and Mamonov, M. (2019). The Formation of Hidden Negative Capital in Banking: A Product imbalance Hypothesis. BOFIT Discussion Papers, N 6.

Mamonov, M. (2017). Hidden 'Holes' in the Capital of Not Yet Failed Banks in Russia: An Estimate of the Scope of Potential Losses. Voprosy Ekonomiki, 7, pp. 42-61. [In Russian]. doi: 10.32609/0042-8736-2017-7-42-61

Mamonov, M. (2018a). Banks' Hidden Negative Capital Before and After the Senior Management Change at the Bank of Russia. Russian Journal of Money and Finance, 77(1), pp. 51-70. doi: 10.31477/rjmf.201801.51

Mamonov, M. (2018b). Hidden 'Holes' in the Capital of Banks and the Supply of Credit to the Real Sector of Economy. Voprosy Ekonomiki, 5, pp. 49-68. [In Russian]. doi: 10.32609/0042-8736-2018-5-49-68

Mamonov, M. (2018c). Lending Channel of Monetary Policy in Russia: Microeconomic Estimates for Retail and Corporative Segments of Credit Market. Journal of the New Economic Association, 1(37), pp. 112-144. [In Russian].

Mamonov, M. (2019). Depleting Net Worth of Russian Banks: Changes in Banks' RiskTaking and the Interest Rate Policy of the Bank of Russia. Voprosy Ekonomiki, 6, pp. 30-55. [In Russian]. doi: 10.32609/0042-8736-2019-6-30-55

Mian, A., Rao, K. and Sufi, A. (2013). Household Balance Sheets, Consumption, and the Economic Slump. Quarterly Journal of Economics, 128(4), pp. 1687-1726. doi: $10.1093 /$ qje/qjt020

Mian, A., Suf, A. and Verner, E. (2017). Household Debt and Business Cycles Worldwide. Quarterly Journal of Economics, 132(4), pp. 1755-1817. doi: 10.1093/qje/qjx017

O'Hara, M. and Shaw, W. (1990). Deposit Insurance and Wealth Effects: The Value of Being 'Too Big to Fail'. Journal of Finance, 45(5), pp. 1587-1600. doi: 10.1111/j.1540-6261.1990.tb03729.x

Pestova, A., Pankova, V., Akhmetov, R. and Goloshchapova, I. (2017). Developing a System of Financial Instability Indices Based on High Frequency Data. Dengi i kredit, 6, pp. 49-58. [In Russian]. Available at: https://rjmf.econs.online/ archive/2017/6/ [accessed on 30 April 2020].

Puhani, P. (2000). The Heckman Correction for Sample Selection and Its Critique. Journal of Economic Surveys, 14(1), pp. 53-68.

Schaeck, K. (2008). Bank Liability Structure, FDIC Loss, and Time to Failure: A Quantile Regression Approach. Journal of Financial Services Research, 33(3), pp. 163-179. doi: 10.1007/s10693-008-0028-5

Stolbov, M., Goloshchapova, I., Solntsev, O., Akhmetov, R., Pankova, V. and Tsepilova, E. (2018). A Cross-Country Comparative Analysis of the Russian Financial Sector Model. Voprosy Ekonomiki, 5, pp. 5-24. [In Russian]. doi: 10.32609/0042-8736-2018-5-5-24

Zhivaikina, A. and Peresetsky, A. (2017). Russian Bank Credit Ratings and Bank License Withdrawal 2012-2016. Journal of the New Economic Association, 4(36), pp. 49-80. [In Russian]. 